Article

\title{
UVB-Stimulated TNF $\alpha$ Release from Human Melanocyte and Melanoma Cells Is Mediated by p38 MAPK
}

\author{
Visalini Muthusamy ${ }^{\dagger}$ and Terrence J. Piva *
}

School of Medical Sciences, RMIT University, PO Box 71, Bundoora VIC 3083, Australia

$\dagger$ Current address: School of Applied Science, Republic Polytechnic, 9 Woodlands Ave 9, Singapore 738964, Singapore; E-Mail: visalini_muthusamy@rp.edu.sg.

* Author to whom correspondence should be addressed; E-Mail: terry.piva@rmit.edu.au; Tel.: +61-3-9925-6503; Fax: +61-3-9925-7083.

Received: 9 July 2013; in revised form: 5 August 2013 / Accepted: 9 August 2013 /

Published: 19 August 2013

\begin{abstract}
Ultraviolet (UV) radiation activates cell signaling pathways in melanocytes. As a result of altered signaling pathways and UV-induced cellular damage, melanocytes can undergo oncogenesis and develop into melanomas. In this study, we investigated the effect of UV-radiation on p38 MAPK (mitogen-activated protein kinase), JNK and NFKB pathways to determine which plays a major role in stimulating TNF $\alpha$ secretion in human HEM (melanocytes) and MM96L (melanoma) cells. MM96L cells exhibited 3.5-fold higher p38 activity than HEM cells at 5 min following UVA + B radiation and 1.6-fold

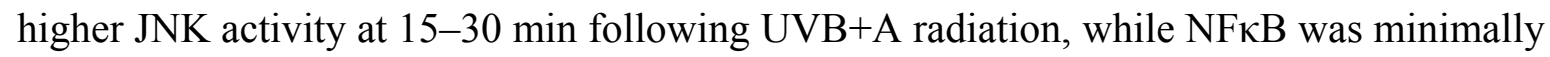
activated in both cells. Irradiated HEM cells had the greatest fold of TNF $\alpha$ secretion (UVB: 109-fold, UVA + B: 103-fold \& UVB+A: 130-fold) when co-exposed to IL1 $\alpha$. The p38 inhibitor, SB202190, inhibited TNF $\alpha$ release by $93 \%$ from UVB-irradiated HEM cells. In the UVB-irradiated MM96L cells, both SB202190 and sulfasalazine (NFkB inhibitor) inhibited TNF $\alpha$ release by $52 \%$. Although, anisomycin was a p38 MAPK activator, it inhibited TNF $\alpha$ release in UV-irradiated cells. This suggests that UV-mediated TNF $\alpha$ release may occur via different $\mathrm{p} 38$ pathway intermediates compared to those stimulated by anisomycin. As such, further studies into the functional role p38 MAPK plays in regulating $\mathrm{TNF} \alpha$ release in UV-irradiated melanocyte-derived cells are warranted.
\end{abstract}


Keywords: UV; melanocytes; melanoma; TNF $\alpha$; p38; JNK; NFкB; anisomycin

\section{Introduction}

The carcinogenic stimulus, ultraviolet (UV) radiation, can transform melanocytes into melanomas, which are an aggressive malignant skin cancer [1,2]. Both UVA and UVB radiation can penetrate into the epidermis and initiate molecular interactions leading to UV-induced responses. Some of these molecular interactions can give rise to genetic alteration, activation/suppression of cell signaling pathways, resulting in either the upregulation or downregulation of cytokine release. The molecular interactions of the B-Raf/extracellular-signal regulated kinase (ERK) pathway in melanoma cells have been widely investigated [1-3]. Unlike ERK, the other mitogen-activated protein kinase (MAPK); p38 MAPK and c-jun terminal kinase (JNK), and nuclear factor- $\kappa \mathrm{B}(\mathrm{NF} \kappa \mathrm{B})$ pathways have not been frequently linked to melanoma incidences [1]. However, there is evidence to suggest that the inhibition/activation of these pathways together with chemotherapeutic agents can elicit cytotoxicity in melanoma cells [4-7]. These pathways have been suggested to also play a role in malignant transformation of melanocytes, although their anti-tumorigenic activities have also been reported [8-12]. Therefore, it is highly likely that besides the B-Raf/ERK pathway, the other MAPK pathways may on their own or in conjunction with ERK play a role in the development and progression of melanoma [3].

Denkert et al. [9] found that the p38 inhibitor, SB203580 caused a $60 \%$ reduction in the invasion of MeWo melanoma cells through a matrigel membrane. Estrada et al. [10] showed that the p38 MAPK/interleukin 8 (IL8) pathway was involved in melanoma cell migration and growth. Through the use of small interfering RNAs (siRNA), which reduced p38 MAPK activity, a decrease in IL8 expression was observed along with reduced migration of melanoma cells in a modified Boyden chamber. This inhibition was overcome by the addition of exogenous IL8, which confirms that this cytokine is downstream of the p38 MAPK pathway governing the migration of melanoma cells [10]. JNK inhibition was also shown to induce $\mathrm{G}_{2} / \mathrm{M}$ cycle arrest and render the melanoma cells susceptible to cell death [8]. Moreover, Ke et al. [13] found that the JNK pathway was involved in loss of cylindromatosis tumor suppressor function in melanoma cells thus enabling tumor growth and metastasis.

The NFאB pathway can be regulated by $\mathrm{TNF} \alpha$ and other molecules resulting in changes to gene transcription [14]. McNulty et al. [15] when comparing Rel A expression observed that there were high levels in the nucleus of melanomas whereas it was mostly localized in the cytoplasm of benign naevus and only low levels were detected in normal melanocytes. In addition, Rel A was shown to play an important role in melanoma cell survival as antisense Rel A phosphorothioate oligonucleotides abrogated its protective effects [16]. Taken together, these findings suggest that the p38 MAPK, JNK and NFKB pathways are involved in both melanoma progression and metastasis.

Apart from changes to cell signaling activity, UV radiation can alter cytokine levels in melanocyte-derived cells [17]. Of interest is tumor necrosis factor- $\alpha$ (TNF $\alpha)$, a proinflammatory cytokine, which may be involved in anti- or pro-tumor activities in melanoma development $[11,18]$. Ivanov et al. [18] found that TNF $\alpha$ promoted cell survival of LU125 melanoma cells as the suppression of its expression led to UVC-induced $\left(0.06 \mathrm{~kJ} / \mathrm{m}^{2}\right)$ cell death. In support of this finding, 
exogenous TNF $\alpha$ was found to inhibit apoptosis in melanoma cells with abrogated B-Raf signaling through the activation of the NFאB pathway [19]. Therefore, it is possible that TNF $\alpha$ and other molecules present in the tumor microenvironment may provide an added advantage for melanoma progression. However, TNF $\alpha$ has also been implicated in anti-tumor activities. It was used as an anti-vascular agent in melanoma cells where induction of TNF $\alpha$ in the tumor endothelium led to a breakdown of tumor vasculature and inhibition of tumor growth in mice [20]. As such, it will be crucial to delineate the pathways involved in mediating $\mathrm{TNF} \alpha$ secretion from melanoma cells to selectively enhance or inhibit its levels.

In this study, we compared the effects of UV radiation on the activation of the p38, JNK and NFKB pathways, as well as TNFa secretion in primary human epidermal melanocytes (HEM) and a melanoma cell line (MM96L). The melanoma cell line was examined to see if the activity of these signaling pathways was altered during oncogenesis. Many studies have used UVC radiation to study cells signaling pathways, which are not physiologically relevant [18,21]. In this study, we used physiological doses, e.g., 1 MED (Minimal Erythemal Dose), to investigate the activation of cell signaling pathways following UV radiation. In addition, we also investigated UV-induced TNF $\alpha$ secretion from these melanocyte-derived cells using specific inhibitors like SB202190 (p38 MAPK inhibitor), SP600125 (JNK inhibitor) and sulfasalazine (NFKB inhibitor), in order to assist in determining which of these signaling pathways play a major role in this process.

\section{Results}

\subsection{Effect of UV Radiation on the Viability of Melanocyte-Derived Cells}

The effect of UV radiation (UVA, UVB, UVA + B or UVB + A) on the viability of HEM and MM96L cells were measured $24 \mathrm{~h}$ post-irradiation using trypan blue exclusion (Figure 1). Cells were exposed to either $40 \mathrm{~kJ} / \mathrm{m}^{2} \mathrm{UVA}$ and/or $2 \mathrm{~kJ} / \mathrm{m}^{2} \mathrm{UVB}$, which is equivalent to the UV component found in 1 MED [22]. These doses are referred to as high dose. The low UV doses used in this study were equivalent to that seen in $0.1 \mathrm{MED}\left(4 \mathrm{~kJ} / \mathrm{m}^{2} \mathrm{UVA}\right.$ and $\left.0.2 \mathrm{~kJ} / \mathrm{m}^{2} \mathrm{UVB}\right)$ and are referred to as low dose. As it was not possible to expose the cells to a simultaneous dose of UVA and UVB radiation together, they were either exposed to UVA first (referred to here as UVA + B) or UVB first (UVB $+A$ ). The purpose of these combined exposures were to see if the first UV type had an effect on the second type.

In this study, HEM cells do not appear to be sensitive to UV radiation as they had a high percentage of attached viable cells after exposure to low dose UV radiation that was similar to that seen in sham-irradiated controls (sham-irradiated control: $88 \%$, low dose UV radiation: $80 \%-83 \%$ ) (Figure 1A). A similar result was seen when the cells were exposed to high dose UV radiation (sham-irradiated control: $88 \%$, high dose UV radiation: 82\%-86\%) (Figure 1A). In MM96L cells, low UV doses induced less cell death than that seen at the high dose (Figure 1B). Cultures exposed to high dose UVA had a higher percentage of attached viable cells when compared to those exposed to the other UV types (sham-irradiated control: 82\%, high dose UVA: 70\%, UVB: 40\%, UVA + B: 39\% UVB + A: 36\%). The UV types containing UVB radiation were shown to be cytotoxic to MM96L cells. Overall, it can be seen that MM96L cells were more sensitive to UV radiation than were HEM cells when they were exposed to high doses of UV radiation (Figure 1). 
Figure 1. Effect of UV-irradiation on the viability of (A) human epidermal melanocytes (HEM) and (B) MM96L cell cultures at $24 \mathrm{~h}$ post-exposure. Cell viability was performed using trypan blue exclusion. Results expressed as the means \pm SD from three independent experiments. Comparisons were made between sham-irradiated control and UV-irradiated cultures using Student's paired $t$-test where significance was recorded as $p \leq 0.05\left(^{*}\right)$.

Legend: $\square$ Attached Viable Cells $\mathbb{N}$ Attached Dead Cells

Detached Viable Cells $\quad$ Detached Dead Cells

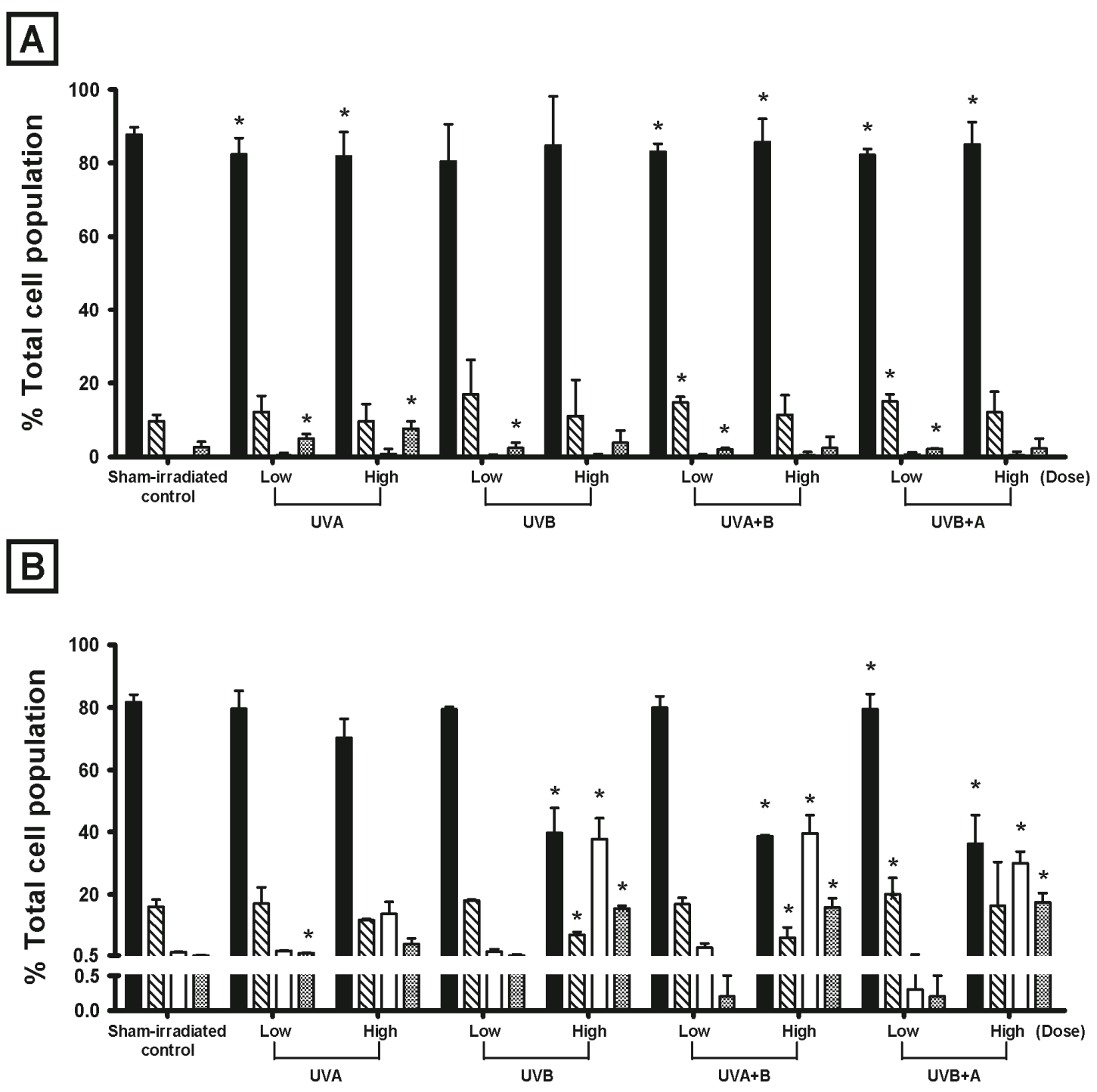

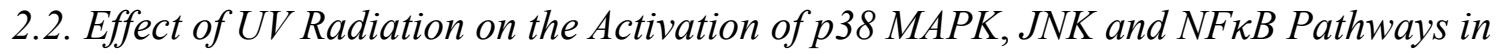
Melanocyte-Derived Cells

The activation of the $\mathrm{p} 38$ MAPK, JNK and NFkB signaling pathways, was observed over the first 120 min following UV radiation in HEM and MM96L cells. These cells were exposed to either a low or a high dose of UVA, UVB, UVA + B or UVB + A radiation to observe the effect these doses and UV types have on activating the signaling pathways in cells that have survived and/or accumulated a certain degree of damage (Figure 1). Once irradiated, the cell cultures were left to incubate for various 
amounts of time and cell protein lysates were extracted at the end of these time points to perform western blots.

\subsection{1. p38 MAPK Pathway}

This pathway is activated following the phosphorylation of p38 MAPK [23]. Therefore, changes in phospho-p38 MAPK expression was measured in HEM and MM96L cells exposed to UV radiation and was expressed as a ratio of the UV-irradiated sample over the sham-irradiated control $(0 \mathrm{~min}=100 \%)$ (Figure 2A). In all cases, the level of phospho-p38 was first standardized against its loading control ( $\beta$-actin) at each measured time point, and these values were used to calculate changes in expression as a result of UV exposure, as stated in the previous sentence.

Figure 2. Effect of UV radiation on phospho-p38 expression in HEM and MM96L cells. (A) A representative western blot probed for phospho-p38 in HEM and MM96L cells post UVB-irradiation. Cell cultures were irradiated with either a (B,C) low (0.1 MED) or (D,E) high (1 MED) dose of UVA, UVB, UVA + B and UVB + A radiation. Cellular proteins were extracted at various time points $(0-120 \mathrm{~min})$ post-irradiation. In each lane $30 \mu \mathrm{g}$ of cell lysate was added. Sham-irradiated control $(0 \mathrm{~min})=100 \%$. Results expressed as the means \pm SD from three independent experiments. Comparisons were made between sham-irradiated controls and UV-irradiated cultures using Student's paired $t$-test where significance was recorded as $p \leq 0.05(\alpha, \beta, \gamma, \delta)$ [UVA $(\alpha)$; UVB $(\beta)$; UVA $+\mathrm{B}(\gamma)$; $\mathrm{UVB}+\mathrm{A}(\delta)]$

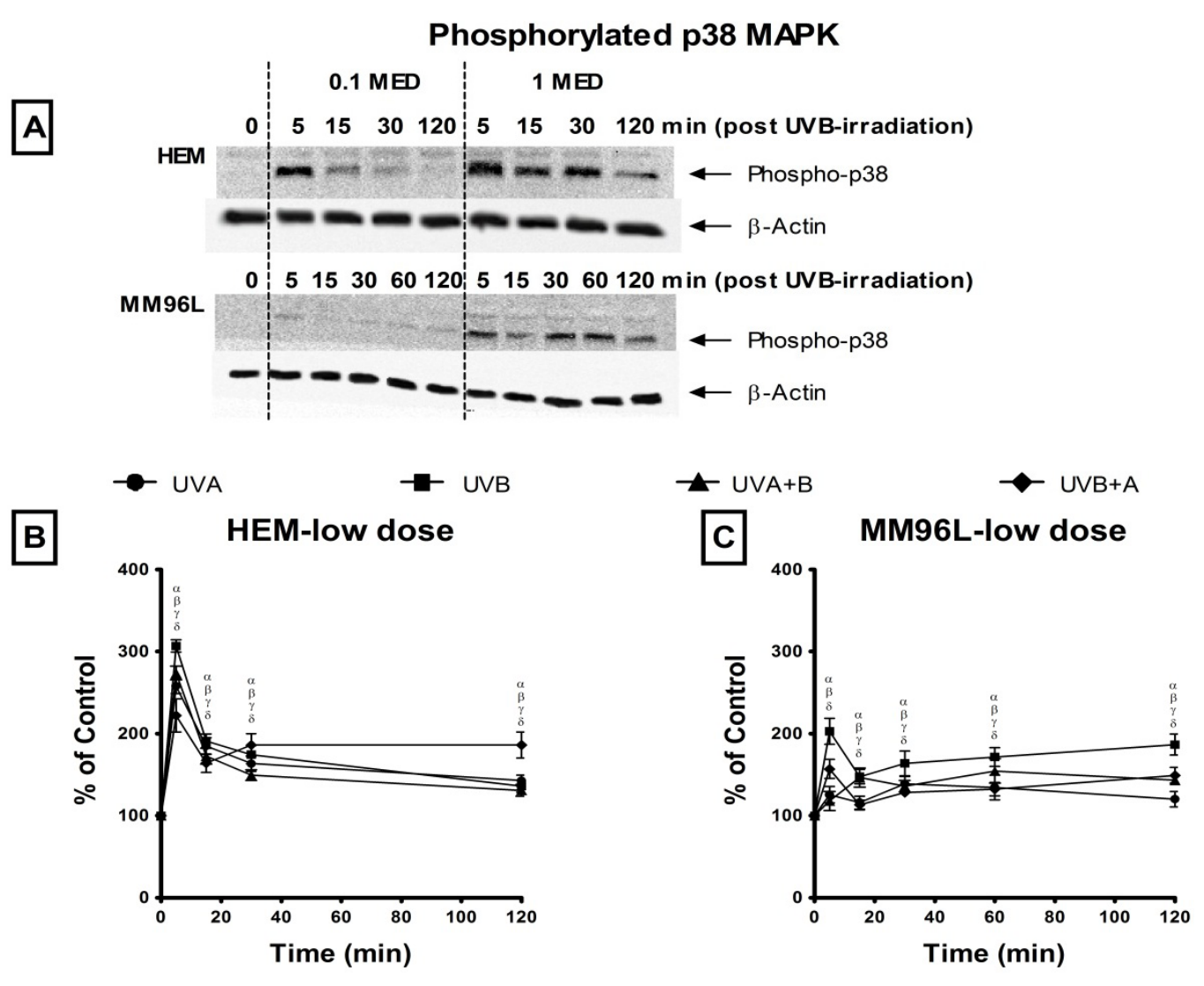


Figure 2. Cont.
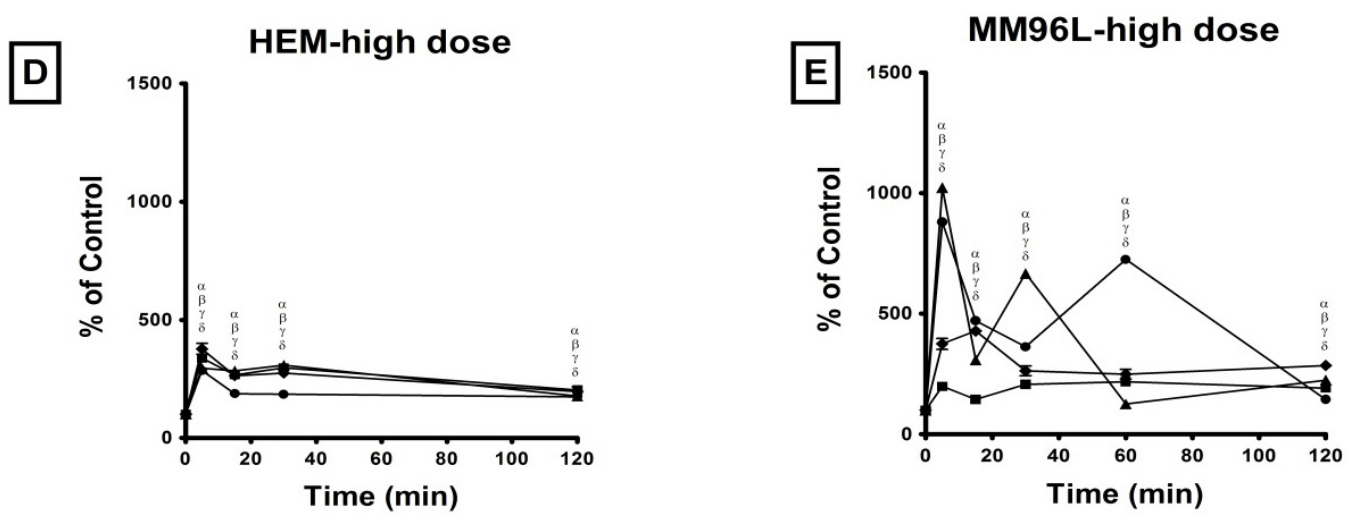

In HEM cells, low dose UV radiation induced an immediate increase in phospho-p38 levels at 5 min post-irradiation with UVB stimulating the highest level (307\% at $5 \mathrm{~min}$ ) than the other UV types (UVA: 258\%, UVA + B: 274\%, UVB + A: 222\%) (Figure 2B). A similar trend was observed after high dose UV radiation where phospho-p38 levels rose to $377 \%$ and $337 \%$ at 5 min post UVB $+A$ and UVB radiation, respectively which was higher than that observed following UVA (286\%) and UVA + B (296\%) radiation (Figure 2D). In addition, high dose UVA radiation induced lower phospho-p38 levels than that of the other UV types as seen between 15 and 120 min post-irradiation.

In MM96L cells, low dose UV radiation induced less than a 2-fold increase in phospho-p38 levels (Figure 2C). In contrast, high dose UV radiation stimulated a greater increase in phospho-p38 levels, which rose to $880 \%$ and $1022 \%$ at 5 min following exposure to UVA and UVA + B radiation, respectively (Figure 2E). These levels remained elevated between 30 and 60 min post-irradiation. After UVB + A radiation, these levels peaked at $15 \mathrm{~min}(423 \%)$ while UVB radiation stimulated low phospho-p38 levels $(<210 \%)$ during this 120 min period. Overall, low dose UV radiation reduced phosphorylation of p38 in MM96L cells compared to HEM cells, however high UV doses induced a dramatic increase in these levels in MM96L cells but not in HEM cells.

\subsubsection{JNK Pathway}

This pathway is activated when the JNK protein is phosphorylated by upstream activators [23]. As both the JNK1 and JNK2 isoforms are predominantly activated in skin cells [24], the expression of both phospho-JNK1 and -JNK2 was observed over 120 min post-exposure in HEM and MM96L cells (Figure 3A). Changes in the level of phospho-JNK1 or -JNK2 were expressed as a percentage of total phospho-JNK (JNK1 and JNK2) levels in sham-irradiated controls ( $0 \mathrm{~min}$ ) (Figure 3A). In all cases, the levels of phospho-JNK1 and JNK2 were first standardized against their loading control ( $\beta$-actin) at each measured time point. In the controls, the level of phospho-JNK1 + -JNK2 was added together and this total was expressed as $100 \%$. The effect of UV exposure on the expression of each subunit at each time point was calculated as a ratio to that seen in the sham-irradiated controls as described above. 
Figure 3. Effect of UV radiation on phospho-JNK1/2 expression in HEM and MM96L cells. (A) A representative western blot probed for phospho-JNK1/2 in HEM and MM96L cells post UVB-irradiation. Cell cultures were irradiated with either a (B,C) low (0.1 MED) or $(\mathbf{D}, \mathbf{E})$ high (1 MED) dose of UVA, UVB, UVA + B and UVB+A radiation. Cellular proteins were extracted at various time points $(0-120 \mathrm{~min})$ post-irradiation. In each lane $30 \mu \mathrm{g}$ of cell lysate was added. Sham-irradiated control ( $0 \mathrm{~min})$ : phospho-JNK1 $+-\mathrm{JNK} 2=100 \%$. Results expressed as the means \pm SD from three independent experiments. Comparisons were made between sham-irradiated controls and UV-irradiated cultures using Student's paired $t$-test where significance was recorded as $p \leq 0.05(\alpha, \beta, \gamma, \delta)$ [UVA $(\alpha)$; UVB $(\beta)$; $\mathrm{UVA}+\mathrm{B}(\gamma) ; \mathrm{UVB}+\mathrm{A}(\delta)]$

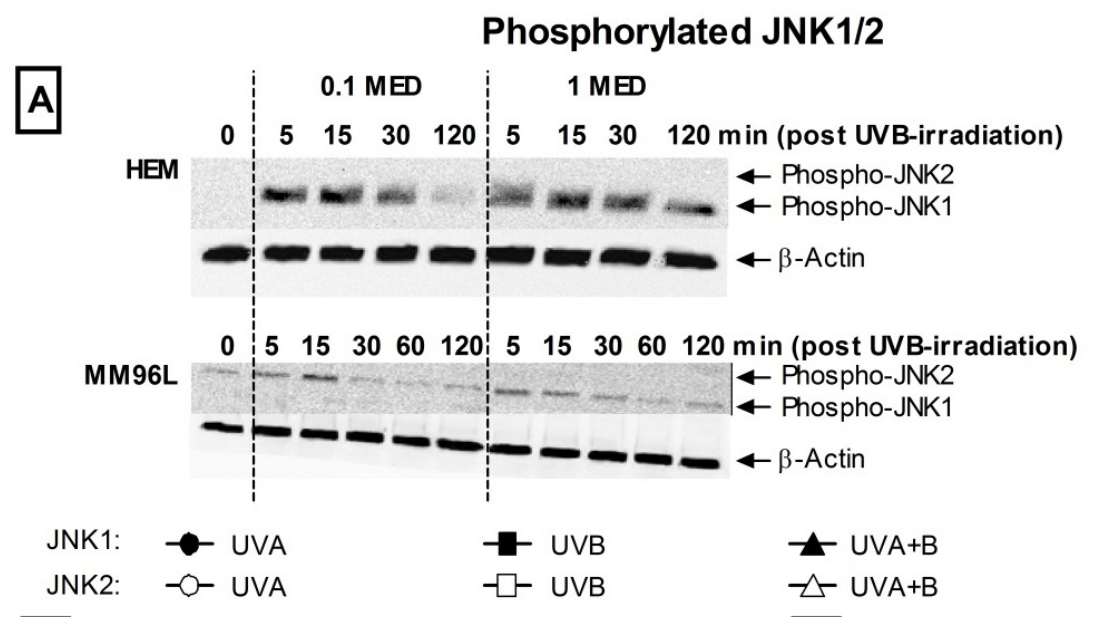

$U V B+A$

JNK2: $\quad-\infty-$ UVA

$\triangle-$ UVA+B

$\checkmark$ UVB+A

$B$

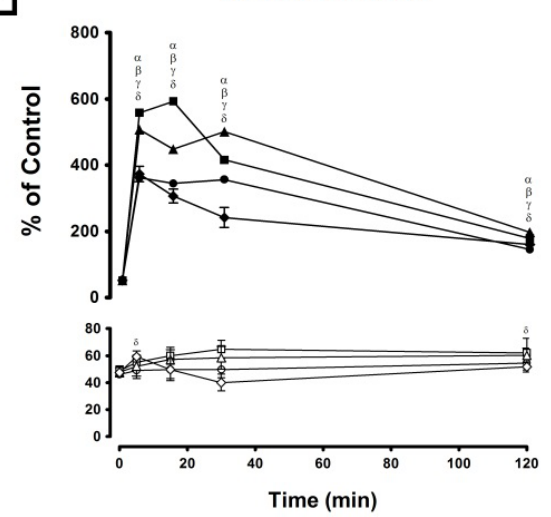

D

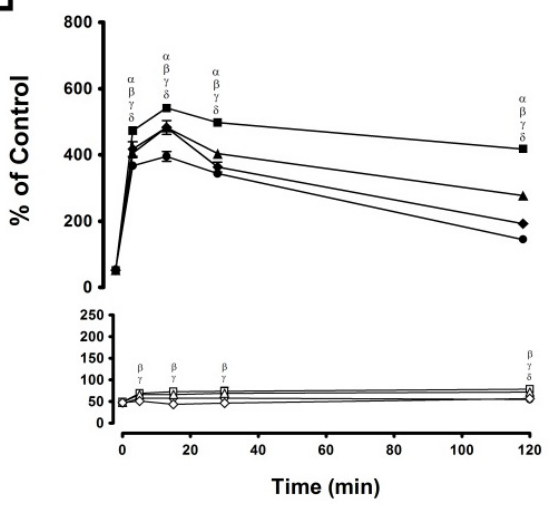

C MM96L-low dose

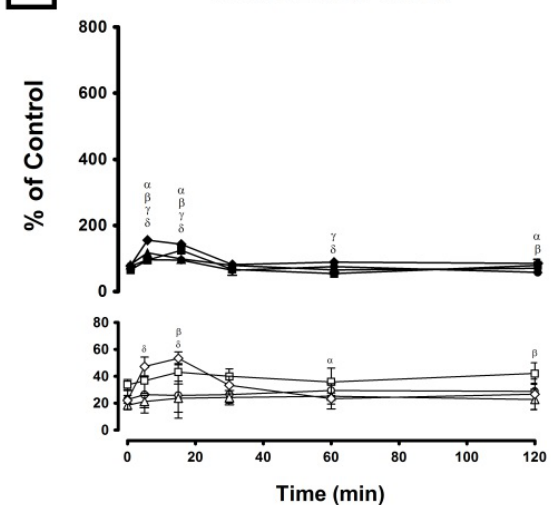

E MM96L-high dose

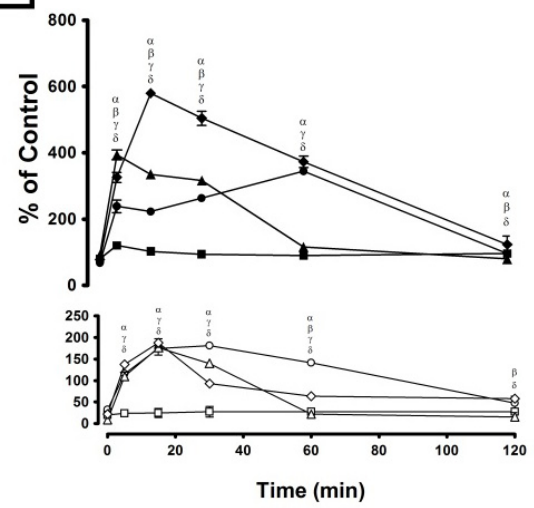


In HEM cells, low dose UV induced a 11-fold ( $576 \%)$ increase in phospho-JNK1 levels between 5 and 15 min following UVB radiation while that after UVA + B radiation remained at 9-fold ( $485 \%)$ until $30 \mathrm{~min}$ before declining to $\sim 188 \%$ (4-fold) at $120 \mathrm{~min}$ post-irradiation (Figure 3B). Following UVA and UVB+A radiation, phospho-JNK levels increased by 7 -fold $(\sim 360 \%)$ at 5 min post-irradiation. While these levels remained the same until 30 min following UVA radiation, that after UVB + A radiation began to decline to $160 \%$ at 120 min post-irradiation. After exposure to high dose UV, the pattern of phospho-JNK1 was similar in HEM cells where these levels peaked at 15 min post-irradiation, declining thereafter to varying degrees irrespective of the UV types used (Figure 3D). UVB radiation induced the highest levels of phospho-JNK1 (542\% at $15 \mathrm{~min}$ ) and remained high at $120 \mathrm{~min}(418 \%)$ post-irradiation while UVA induced the lowest levels (395\% at $15 \mathrm{~min}$ and $145 \%$ at $120 \mathrm{~min}$ ). UVA $+\mathrm{B}$ and $\mathrm{UVB}+\mathrm{A}$ radiation induced a 9-fold (483\%) increase in these levels, which fell to $277 \%$ (UVA + B) and $193 \%(\mathrm{UVB}+\mathrm{A})$ at 120 min post-irradiation. Phospho-JNK2 levels were less than 2-fold in HEM cells exposed to either low or high dose UV radiation (Figure 3B,D).

In MM96L cells, phospho-JNK1 levels were highest (155\% at $5 \mathrm{~min}$ ) following low UVB+A radiation compared to the other UV types (UVA: $97 \%$ at $5 \mathrm{~min}, \mathrm{UVB}: 125 \%$ at $15 \mathrm{~min}$, UVA $+\mathrm{B}$ : $117 \%$ at $5 \mathrm{~min})$ and these levels returned to control values $(0 \mathrm{~min}=\sim 76 \%)$ at $30 \mathrm{~min}$ post-irradiation, irrespective of the UV type used (Figure 3C). Minimal phosphorylation of JNK2 was observed following exposure to low dose UV radiation (Figure 3C). In these cells, high dose UV radiation stimulated a rapid and sustained activation of phospho-JNK1 until 60 min post-irradiation except for those cells exposed to UVB radiation (Figure 3E). UVB + A radiation triggered a 7 -fold $(580 \%$ at $15 \mathrm{~min})$ increase in phospho-JNK1 levels while there was only a 4 to 5 -fold $(\sim 369 \%)$ increase following UVA (60 $\mathrm{min})$ and UVA + B $(5 \mathrm{~min})$ radiation before it returned to baseline values $(0 \mathrm{~min}=\sim 80 \%)$. Phospho-JNK1 levels were elevated less than 2-fold following UVB radiation, while phospho-JNK2 levels were also elevated (4-8 fold) after high dose UV-irradiation except for UVB-irradiated MM96L cells (Figure 3E). In general, HEM cells had higher phospho-JNK levels than did MM96L cells following low dose UV radiation but after high dose UV radiation, the former had lower levels except for those cells exposed to UVB radiation.

\subsubsection{NFкB Pathway}

The NFкB dimeric complex is freed when $\mathrm{I} \kappa \mathrm{B} \alpha$ is phosphorylated and removed by the proteasome [14,25]. The addition of MG115 (proteasome inhibitor) prevents the degradation of phospho-I $\mathrm{K} \mathrm{B} \alpha$ thereby allowing for its accumulation within the cell [26]. As such, higher levels of

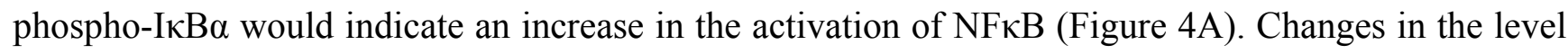
of phospho-I $\kappa \mathrm{B} \alpha$ was expressed as a ratio of the UV-irradiated sample over its corresponding sham-irradiated control $(0 \mathrm{~min}=100 \%)($ Figure $4 \mathrm{~A})$. 
Figure 4. Effect of UV radiation on phospho-IкB $\alpha$ expression in HEK, HaCaT and Colo16 cells. (A) A representative western blot probed for phospho-IкB $\alpha$ in HEK and MM96L cells post UVB-irradiation. Cell cultures were irradiated with either a $(\mathbf{B}, C)$ low $(0.1 \mathrm{MED})$ or $(\mathbf{D}, \mathbf{E})$ high $(1 \mathrm{MED})$ dose of UVA, UVB, UVA $+\mathrm{B}$ and $\mathrm{UVB}+\mathrm{A}$ radiation. Cellular proteins were extracted at various time points $(0-120 \mathrm{~min})$ post-irradiation. In each lane $30 \mu \mathrm{g}$ of cell lysate was added. Sham-irradiated control $(0 \mathrm{~min})=100 \%$. Results expressed as the means \pm SD from three independent experiments. Comparisons were made between sham-irradiated controls and UV-irradiated cultures using Student's paired $t$-test where significance was recorded as $p \leq 0.05(\alpha, \beta, \gamma, \delta)$ [UVA $(\alpha)$; UVB $(\beta)$; UVA $+\mathrm{B}(\gamma)$; $\mathrm{UVB}+\mathrm{A}(\delta)]$.

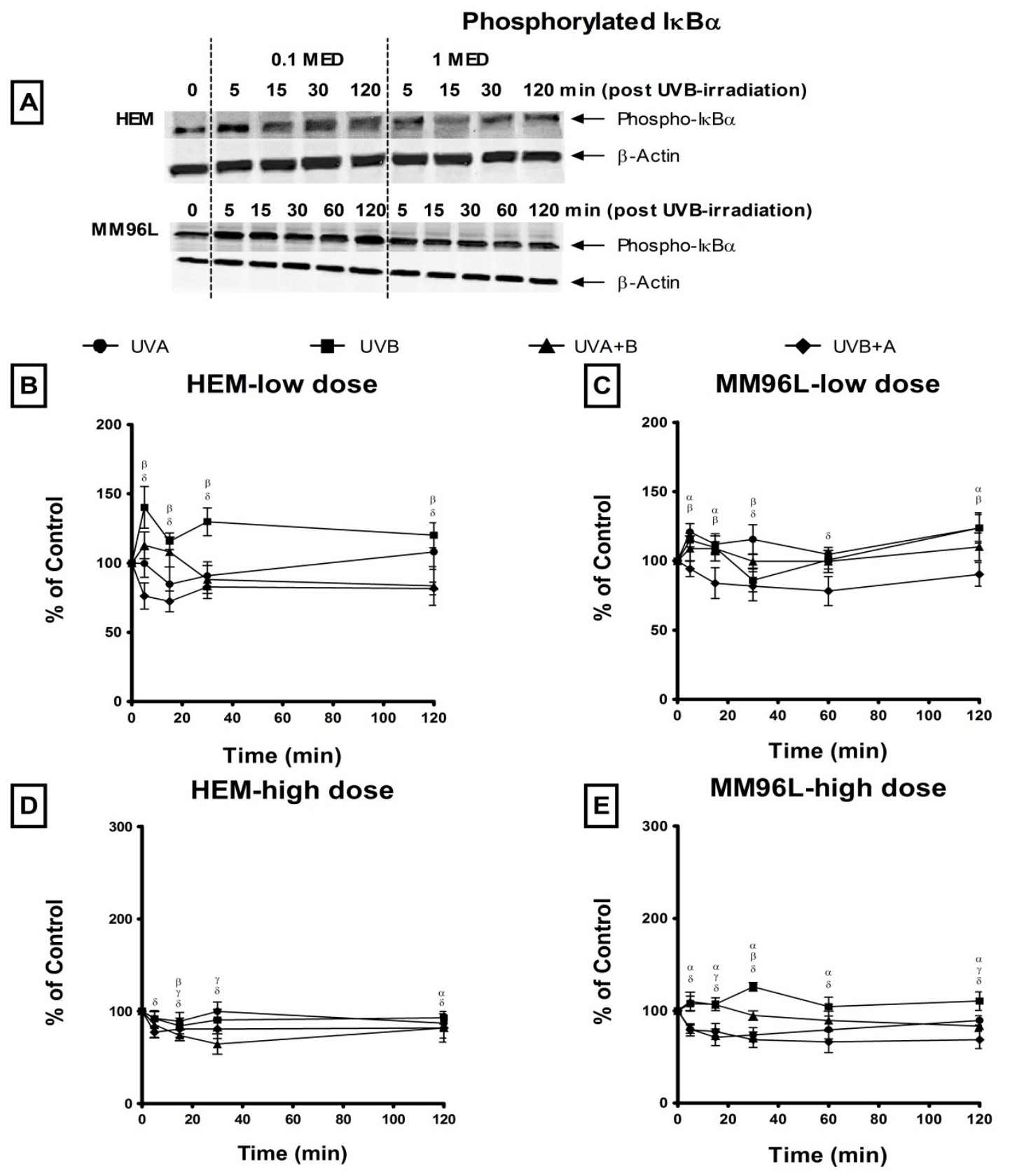


In HEM cells, following low dose UVB radiation, there was a slight increase in phospho-IкB $\alpha$ levels at $5 \mathrm{~min}(140 \%)$ post-irradiation while UVA and UVA $+\mathrm{B}$ radiation did not significantly after these levels throughout the $120 \mathrm{~min}$ time period (Figure 4B). In addition,

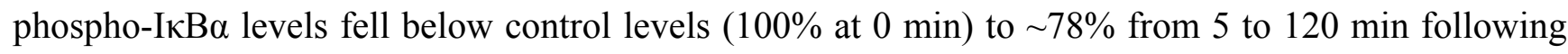
UVB + A radiation. In these cells, high dose UV radiation did not stimulate an increase in phospho-I $\kappa \mathrm{B} \alpha$ levels as these levels were below control levels ( $\leq 100 \%)$ (Figure 4D). In MM96L cells, low dose UVA and UVB radiation induced a slight increase $(<120 \%)$ in phospho-I $\kappa \mathrm{B} \alpha$ levels but these levels fell below control values $(0 \mathrm{~min}=100 \%)$ to $86 \%$ when cells were exposed to $\mathrm{UVB}+\mathrm{A}$ radiation (Figure $4 \mathrm{C}$ ). After high dose UV radiation, phospho-IкB $\alpha$ remained below control levels except for that following UVB radiation which peaked at $30 \mathrm{~min}$ (126\%) post-irradiation (Figure 4E). In general, UV radiation induced little or no phosphorylation of $\mathrm{I} \kappa \mathrm{B} \alpha$ in either HEM or MM96L cells.

\subsection{Effect of UV Radiation and IL1a on TNFa Release in Melanocyte-Derived Cells}

Cell signaling pathways are required to regulate the levels of cytokines present in the microenvironment of the skin in response to UV radiation. A range of cytokines including IL1, IL4, IL6, IL8, IL10, IL12, IL15 and TNF $\alpha$ are secreted by cells found in the epidermis and dermis [23]. Of these cytokines, IL1 $\alpha$ and TNF $\alpha$ are considered to play an important role in UV-induced inflammatory and immunological responses [23,27-29]. Bashir et al. [30] found that IL1 $\alpha$ $(10 \mathrm{ng} / \mathrm{mL})$ upregulated TNF $\alpha$ levels via increased gene transcription following UVB radiation in keratinocytes [30]. The production of IL1 $\alpha$ by keratinocytes, fibroblasts and other cell types in the skin can act in a paracrine fashion to stimulate melanocyte cells. In sham- and UV-irradiated HEM cells, IL1 $\alpha(10 \mathrm{ng} / \mathrm{mL})$ did not significantly affect the activation of the JNK and NFKB pathways but induced a $~ 3$-fold increase in phospho-p38 levels at 5-30 min post high dose UV-irradiation (results not shown). In MM96L cells, IL1 $\alpha$ stimulation increased phospho-JNK1 and p38 levels by $\sim 2$-fold in the first $30 \mathrm{~min}$ of high dose UV-irradiation but no changes in phospho-I $\mathrm{B} \alpha$ levels were observed (results not shown). We then examined the effect exogenous IL1 $\alpha$ had on TNF $\alpha$ secretion in cells exposed to 1 MED UV radiation as low dose UV radiation did not stimulate detectable amounts of secreted TNF $\alpha$.

Sham-irradiated HEM cells secreted very low levels of TNF $\alpha$ ( $7 \pm 3 \mathrm{pg} / \mathrm{mg}$ cell protein) and these levels only increased slightly ( $\sim 10 \mathrm{pg} / \mathrm{mg}$ cell protein) following UV radiation (Figure $5 \mathrm{~A})$. When IL1 $\alpha$ was added immediately after UVA-irradiation, TNF $\alpha$ levels increased by 2 -fold (control + IL1 $\alpha$ : $67 \pm 4 \mathrm{pg} / \mathrm{mg}$ cell protein, UVA + IL1 $\alpha: 122 \pm 31 \mathrm{pg} / \mathrm{mg}$ cell protein). There was a dramatic increase in these levels when IL1 $\alpha$-treated HEM cells were exposed to UVB $(1309 \pm 206 \mathrm{pg} / \mathrm{mg}$ cell protein), UVA + B (1339 $\pm 142 \mathrm{pg} / \mathrm{mg}$ cell protein) and UVB + A (1296 $\pm 147 \mathrm{pg} / \mathrm{mg}$ cell protein $)$ radiation (Figure 5A). In MM96L cells, low levels of TNF $\alpha$ were secreted from both sham- $(2 \pm 0.2 \mathrm{pg} / \mathrm{mg}$ cell protein) and UV-irradiated cells ( $\sim 5 \mathrm{pg} / \mathrm{mg}$ cell protein) (Figure $5 \mathrm{~B})$. The addition of IL1 $\alpha$ increased $\mathrm{TNF} \alpha$ levels to $\sim 30 \mathrm{pg} / \mathrm{mg}$ cell protein in the sham- or UVA-irradiated cells. After UVB and UVA $+\mathrm{B}$ radiation, IL1 $\alpha$-treated cells secreted $580 \pm 69$ and $525 \pm 95 \mathrm{pg} / \mathrm{mg} \mathrm{TNF} \alpha$, respectively while those cells exposed to UVB + A radiation released less $\mathrm{TNF} \alpha(192 \pm 23 \mathrm{pg} / \mathrm{mg}$ cell protein) (Figure $5 \mathrm{~B})$. Overall, less TNF $\alpha$ was secreted from cells exposed to UVA radiation. The degree by which IL1 $\alpha$ increased TNF $\alpha$ secretion from the irradiated cells was greater in HEM cells than compared to MM96L cells (Table 1). 
Figure 5. Effect of UV radiation and IL1 $\alpha$ on the release of TNF $\alpha$ in (A) HEM and (B) MM96L cells. Cell cultures were irradiated with the equivalent of 1 MED radiation and treated in the presence or absence of $10 \mathrm{ng} / \mathrm{mL}$ IL1 $\alpha$. The media was collected $24 \mathrm{~h}$ post-irradiation and assayed for TNF $\alpha$. Results expressed as the means \pm SD from three independent experiments. Statistical analysis was performed using a Student's paired $t$-test where significance was recorded as $p \leq 0.05$. (*) Significant difference between Control and UV-irradiated samples. $(f)$ Significant difference between Control and UV-irradiated samples treated with IL1 $\alpha$.

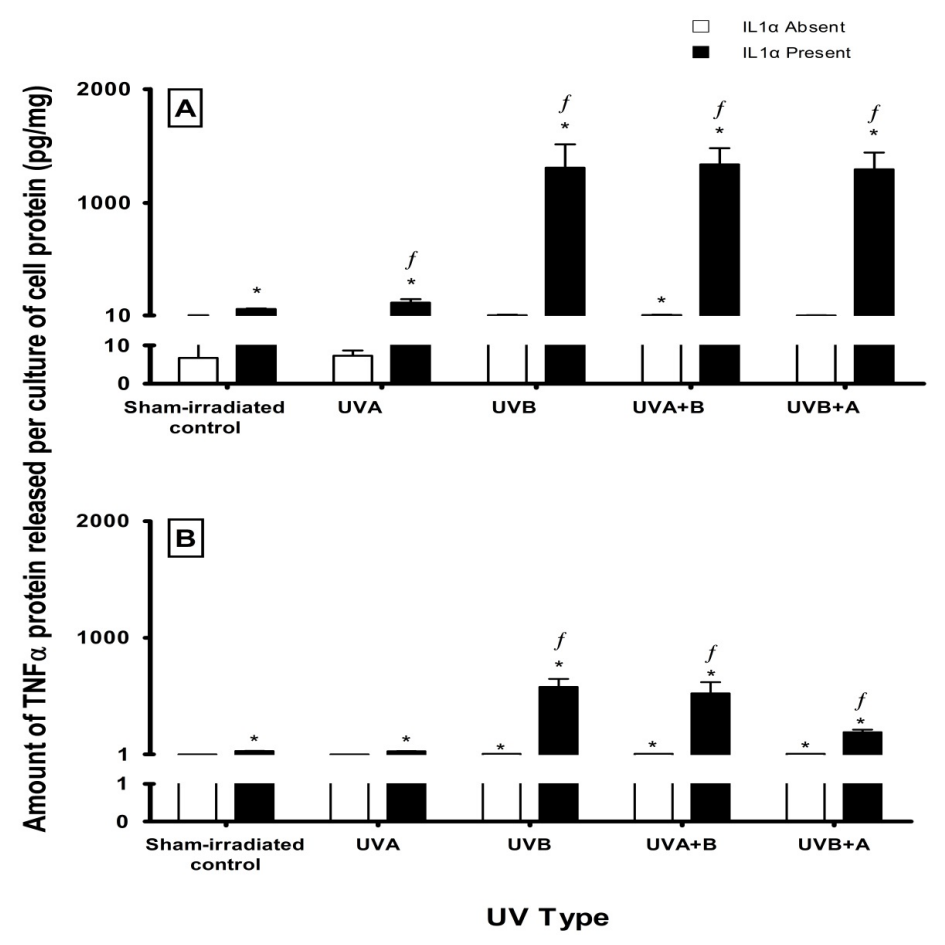

Table 1. Effect of IL $1 \alpha$ on the release of TNF $\alpha$ from UV-irradiated melanocyte-derived cell line.

\begin{tabular}{cccccc}
\hline Cell Line & Sham & UVA & UVB & UVA + B & UVB + A \\
\hline HEM & $10 \pm 4$ & $17 \pm 6$ & $109 \pm 40$ & $103 \pm 26$ & $130 \pm 24$ \\
MM96L & $15 \pm 1$ & $14 \pm 4$ & $97 \pm 22$ & $88 \pm 23$ & $32 \pm 4$ \\
\hline
\end{tabular}

All values are calculated as the fold-increase \pm SD of UV-irradiated cells treated with IL1 $\alpha$ compared to their corresponding irradiated counterparts. Values calculated from the data represented in Figure 5.

\subsection{Effect of Pathway Specific Inhibitors on UV-Induced TNFa Release in Melanocyte-Derived Cells}

In order to observe which signaling pathway was involved in UV-induced TNF $\alpha$ release, ELISAs were performed to quantify the level of TNF $\alpha$ released from HEM and MM96L cells treated with either a p38 (SB202190), JNK (SP600125) or NFKB (sulfasalazine) inhibitor. Since high dose UVB radiation increased the secretion of TNFa in HEM and MM96L cells (Figure 5), this study was performed using cells only exposed to high dose UVB radiation. The chosen inhibitor doses did not affect the viability of these cells except for sulfasalazine and SP600125, which induced a slight decrease $(<10 \%)$ in the viability of UVB-irradiated HEM and MM96L cells (results not shown). The cell cultures were treated with the inhibitor for $1 \mathrm{~h}$ prior to receiving 1 MED UVB-irradiation 
$\left(2 \mathrm{~kJ} / \mathrm{m}^{2}\right)$. After UVB exposure, the cell cultures were incubated with the specific inhibitors for $24 \mathrm{~h}$ in the presence or absence of IL1 $\alpha(10 \mathrm{ng} / \mathrm{mL})$.

In HEM cells, unirradiated cultures treated with either the signaling inhibitors secreted similar amounts of TNF $\alpha$ compared to untreated controls (Figure 6A). SB202190 (2.5 $\mu \mathrm{M})$ inhibited the release of $\mathrm{TNF} \alpha(31 \%$ inhibition) from UVB-irradiated cells compared to their untreated irradiated cohorts (16 $\pm 4 \mathrm{pg} / \mathrm{mg}$ cell protein). This inhibition was more pronounced when these UVB-irradiated cells were stimulated with IL1 $\alpha$. The irradiated cells secreted $1343 \pm 51 \mathrm{pg} / \mathrm{mg}$ TNF $\alpha$ after $24 \mathrm{~h}$, however when these cultures were treated with SB202190, TNF $\alpha$ secretion was inhibited by $94 \%$. Neither SP600125 nor sulfasalazine inhibited TNF $\alpha$ secretion from the UVB-irradiated HEM cells either in the presence or absence of IL1 $\alpha$.

Figure 6. Effect of pathway specific inhibitors on TNF $\alpha$ release from (A) HEM and (B) MM96L cells at $24 \mathrm{~h}$ post UVB-irradiation $\left(2 \mathrm{~kJ} / \mathrm{m}^{2}\right)$. The cells were incubated with the specific inhibitors for $1 \mathrm{~h}$ prior to high dose UVB exposure. After UVB exposure, the cells were incubated for $24 \mathrm{~h}$ with the specific inhibitors and treated with or without $10 \mathrm{ng} / \mathrm{mL}$ of IL1 $\alpha$. Results expressed as the means \pm SD from triplicate samples. Statistical analysis was performed using a Student's paired $t$-test where significance was recorded as $p \leq 0.05$. $\left(^{\dagger}\right)(*)$ Significant difference between untreated control and inhibitor treated sample in the absence $(\theta)$ or presence $\left({ }^{\wedge}\right)$ of IL $1 \alpha$.

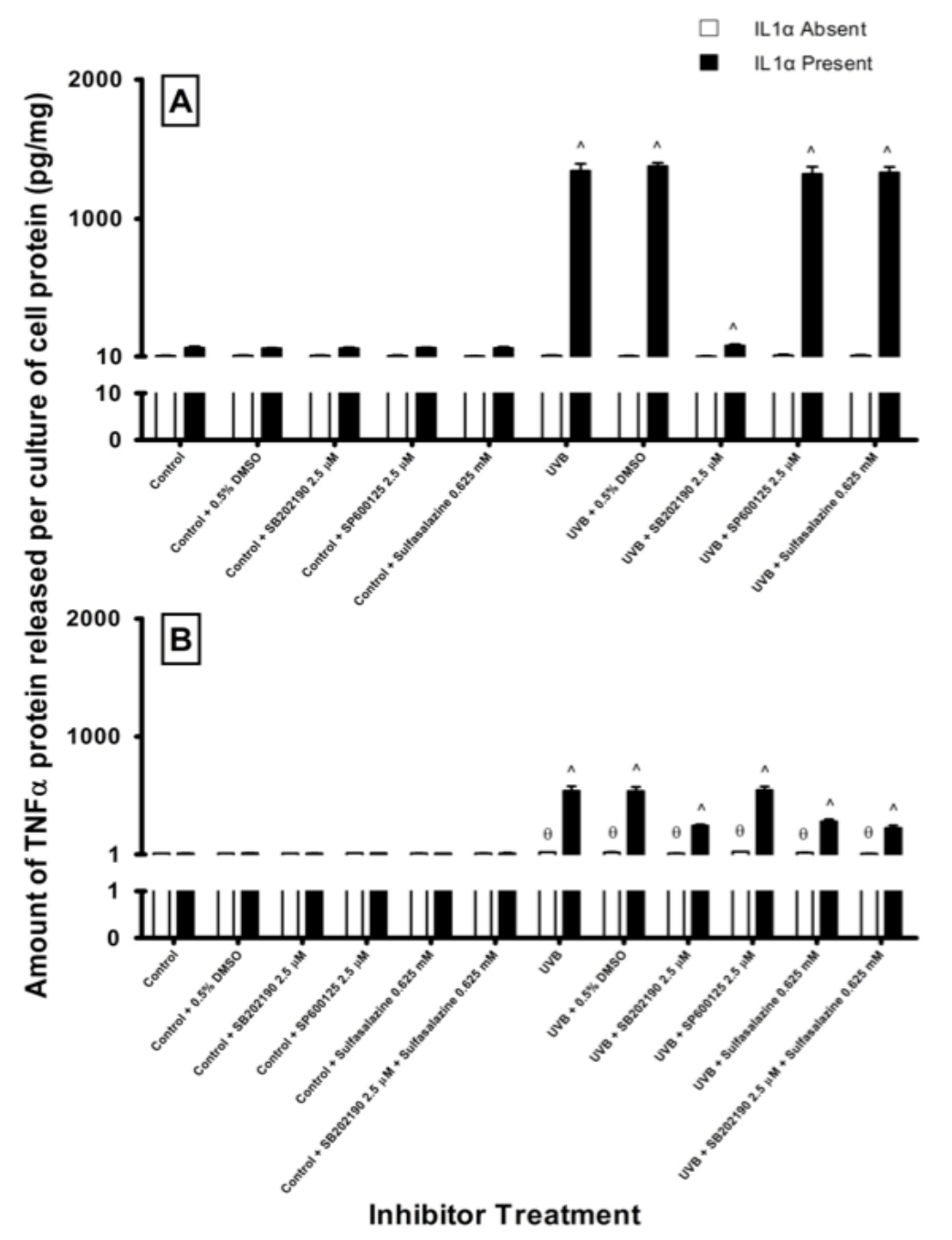


In MM96L cells, pathway specific inhibitors had no effect on TNF $\alpha$ secretion in sham-irradiated cells (Figure 6B). UVB-irradiated MM96L cells secreted $20 \pm 1 \mathrm{pg} / \mathrm{mg}$ TNF $\alpha$, and this fell by 55\% when these cells were treated with $2.5 \mu \mathrm{M}$ SB202190. UVB-irradiated MM96L cells incubated in the presence of IL1 $\alpha$, secreted $539 \pm 40 \mathrm{pg} / \mathrm{mg}$ TNF $\alpha$ over $24 \mathrm{~h}$. The addition of SB202190 to these cells caused a significant reduction in the secretion of TNF $\alpha$ (55\% inhibition). SP600125 did not inhibit the release of TNFa from UVB-irradiated MM96L cells either in the presence or absence of IL1 $\alpha$ (Figure 6B).

$0.625 \mathrm{mM}$ Sulfasalazine slightly inhibited TNF $\alpha$ release from UVB-irradiated MM96L cells by $25 \%$ when compared to their untreated irradiated cohort $(20 \mathrm{pg} / \mathrm{mg}$ cell protein). When the irradiated cells were treated with IL $1 \alpha$, sulfasalazine inhibited TNF $\alpha$ secretion by $48 \%$ compared to uninhibited cells treated with IL1 $\alpha$ (539 $\pm 40 \mathrm{pg} / \mathrm{mg}$ cell protein). There was an additive effect observed when SB202190 and sulfasalazine were both added to the irradiated cells treated with IL1 $\alpha$, where TNF $\alpha$ levels fell by $58 \%$. The results suggest that the p38 MAPK pathway is involved in UVB-mediated $\mathrm{TNF} \alpha$ release in both cell types.

Anisomycin, a known activator of the p38 MAPK pathway, was used to confirm if the p38 MAPK-mediated TNF $\alpha$ release is a UV specific response (Figure 7A) [31]. There was a dose-dependent decrease in the viability of attached cells treated with anisomycin $(20-100 \mu \mathrm{M})$ in sham- or UVB-irradiated HEM (80\%-25\%) or MM96L cells (60\%-7\%) (results not shown). In sham-irradiated HEM cells, anisomycin $(20-100 \mu \mathrm{M})$ increased phospho-p38 levels by 3 - to 4-fold compared to that of untreated controls (Figure 7B). When IL1 $\alpha$ was added to these cultures, there was a further increase (5- to 8-fold) of phospho-p38 levels compared to that seen in the untreated control. In UVB-irradiated HEM cells, there was a 3-fold increase in phospho-p38 levels compared to that seen in sham-irradiated controls (Figure 7D). When anisomycin $(20-100 \mu \mathrm{M})$ was added to UVB-irradiated cells, it resulted in a $\sim 2$-fold increase in phospho-p38 levels. A similar result was also seen when anisomycin was added to UVB-irradiated cells treated with IL1 $\alpha$ (Figure 7D).

In MM96L cells, low dose anisomycin $(20 \mu \mathrm{M})$ increased phospho-p38 levels by 2-fold compared to that of untreated controls (Figure 7C). However, increasing anisomycin concentrations resulted in a drop in phospho-p38 levels (Figure 7C). When IL1 $\alpha$ was added to the unirradiated cells, phospho-p38 levels were only higher in those cells treated with $20 \mu \mathrm{M}$ anisomycin (Figure 7C). In UVB-irradiated MM96L cells, anisomycin $(20-100 \mu \mathrm{M})$ increased phospho-p38 levels by 2- to 4-fold compared to that seen in the untreated irradiated cells (Figure 7E). Phospho-p38 levels fell when IL1 $\alpha$ was added to anisomycin treated irradiated cells (Figure 7E). The results show that anisomycin activated the p38 pathway in HEM and MM96L cells.

When anisomycin was added to sham- or UVB-irradiated HEM and MM96L cells, almost no increase in TNFa secretion was observed (Figure 8). A similar result was also observed for cells treated with IL1 $\alpha$. Even though anisomycin did activate the phosphorylation of p38 MAPK (Figure 7), it did not enhance TNF $\alpha$ release from UVB-irradiated HEM and MM96L cells in the presence or absence of IL1 $\alpha$, which suggests that the downstream events activated by UV radiation differ to that of anisomycin. However, in UVB-irradiated cells treated with IL1 $\alpha$, anisomycin addition resulted in a 98\% reduction in TNF $\alpha$ released from both HEM and MM96L cells. 
Figure 7. The effect of anisomycin on the expression of phospho-p38 protein in HEM and MM96L cells. Representative western blots probed for phospho-p38 in (A,C) HEM and (B,D) MM96L cells treated with anisomycin. (E,F) Sham and $(\mathbf{G}, \mathbf{H})$ UVB-irradiated $\left(2 \mathrm{~kJ} / \mathrm{m}^{2}\right)$ cell cultures treated with or without $10 \mathrm{ng} / \mathrm{mL}$ of IL $1 \alpha$ were incubated with anisomycin for $15 \mathrm{~min}$. Results expressed as the means \pm SD from triplicate samples. Statistical analysis was performed using a Student's paired $t$-test where significance was recorded as $p \leq 0.05$. Significant difference between untreated control and anisomycin treated sample in the $(*)$ absence or $(f)$ presence of IL1 $\alpha$. Significant difference between UVB-irradiated untreated sample and anisomycin treated irradiated sample in the $(\theta)$ absence or $\left(^{\wedge}\right)$ presence of IL1 $\alpha$.
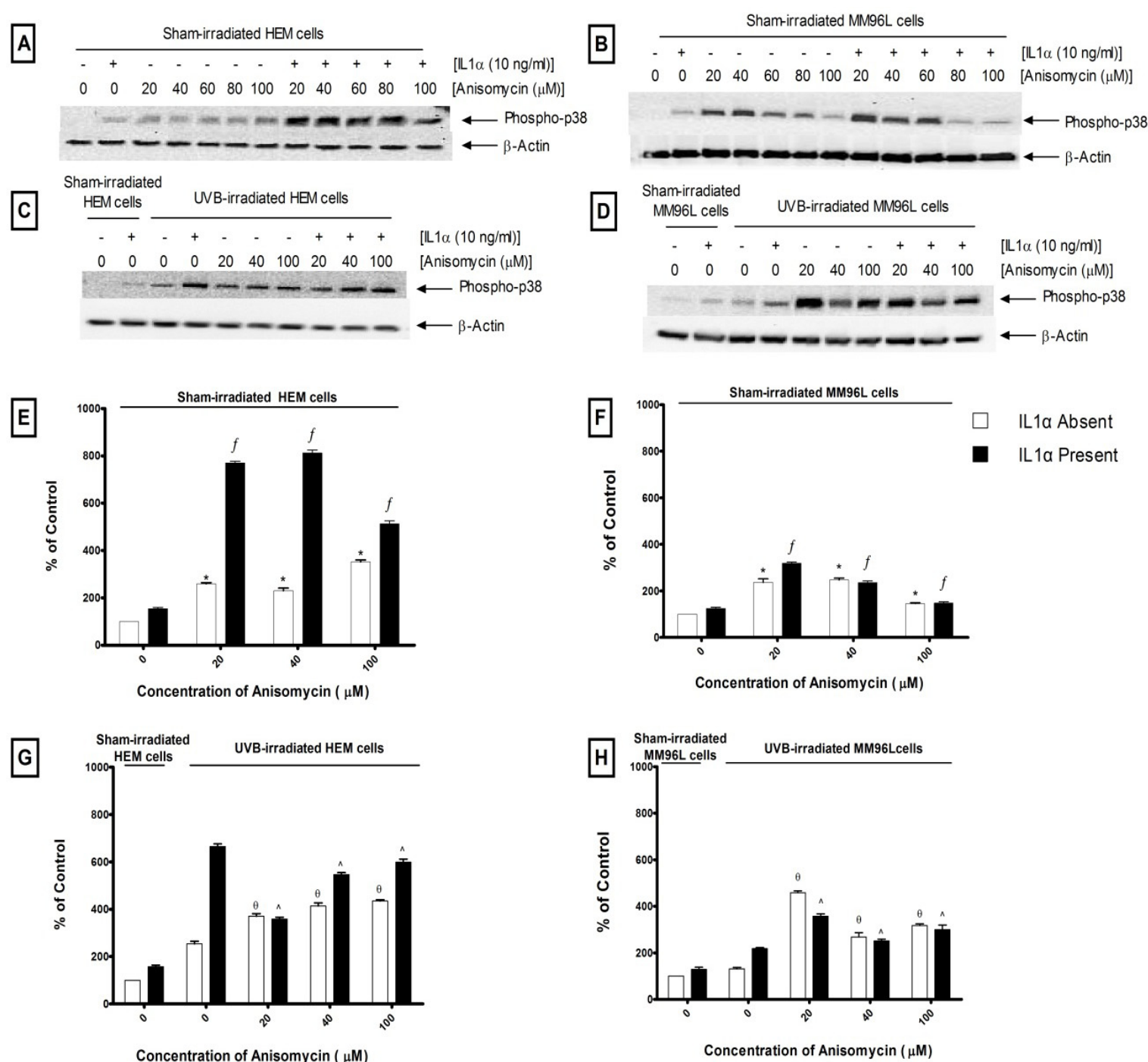

Concentration of Anisomycin ( $\mu \mathrm{M})$

Concentration of Anisomycin $(\mu \mathrm{M})$ 
Figure 8. The effect of anisomycin on TNF $\alpha$ release in (A) HEM and (B) MM96L cells at $24 \mathrm{~h}$ post-treatment. Cell cultures were treated with either 20 or $40 \mu \mathrm{M}$ anisomycin in sham-irradiated or UVB-irradiated $\left(2 \mathrm{~kJ} / \mathrm{m}^{2}\right)$ cells in the presence or absence of $10 \mathrm{ng} / \mathrm{mL}$ of IL $1 \alpha$. Results expressed as the means \pm SD from triplicate samples. Statistical analysis was performed using a Student's paired $t$-test where significance was recorded as $p \leq 0.05$. Significant difference between untreated control and anisomycin treated sample in the $(*)$ absence or $(f)$ presence of IL1 $\alpha$. Significant difference between UVB-irradiated untreated sample and anisomycin treated UV-irradiated samples in the $(\theta)$ absence or $\left(^{\wedge}\right)$ presence of IL1 $\alpha$.

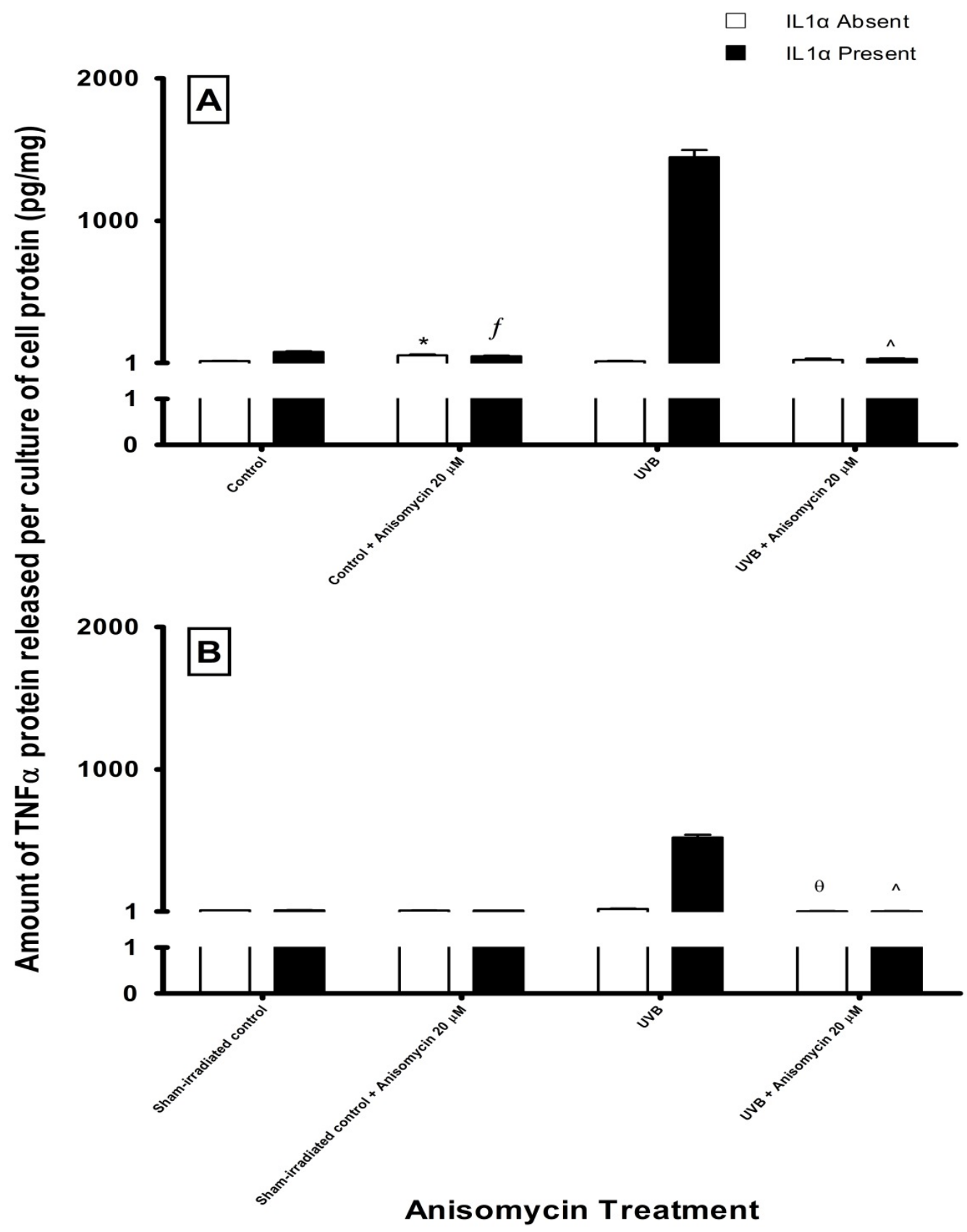




\section{Discussion}

\subsection{Choice of Cell Types and UV Radiation}

Two different human melanocyte-derived cell types, HEM (Human Epidermal Melanocytes) and MM96L (Malignant Melanoma) cells were used in this study. The MM96L cells have acquired a B-Raf V600E mutation and do not express the p16 protein but they do possess functional N-Ras and PTEN [32,33]. These cells were cultured from a secondary tumor of a 66 year old female melanoma patient, however the location of which was not stated [34]. HEM and MM96L cells were used to observe how normal and cancerous melanocytes responded to UV radiation. These cells were exposed to a low and high dose of UVA, UVB, UVA + B and UVB + A radiation. The dose used in this study was that UV component found in 1 MED sunlight $\left(40-50 \mathrm{~kJ} / \mathrm{m}^{2}\right)$ where a high dose UVA was $40 \mathrm{~kJ} / \mathrm{m}^{2}$ and UVB was $2 \mathrm{~kJ} / \mathrm{m}^{2}$, while the low doses used corresponded to the UV components seen in 0.1 MED [22].

HEM cells were less susceptible to different UV types or doses than were MM96L cells (Figure 1), and this suggests that these cells either have a more efficient DNA repair mechanism or certain factor(s) rendering them less susceptible to UV radiation. This factor is most likely to be melanin, which is a UV-absorbing pigment synthesized in melanocytes [35,36]. Kobayashi et al. [37] observed that melanin forms supranuclear caps around the nucleus protecting the DNA from harmful UV radiation [37]. As such, although melanocytes possess a weaker antioxidant defence mechanism than do keratinocytes, they are less sensitive to UV-induced damage [38].

The highest levels of cell death were observed in cells exposed to high dose UVB, UVA $+B$ and UVB + A radiation. Since UVA alone inflicted less damage to the cells, the UVB component is predominant over UVA in the combination of $U V A+B$ or $U V B+A$ radiation used (Figure 1B). Koch-Paiz et al. [39] found that UVA $\left(50 \mathrm{~kJ} / \mathrm{m}^{2}\right)$ triggered a weaker genetic response than UVB $\left(0.1 \mathrm{~kJ} / \mathrm{m}^{2}\right)$ radiation in MCF-7 cells. In mouse embryonic fibroblast cells, UVA-induced $\left(180 \mathrm{~kJ} / \mathrm{m}^{2}\right)$ DNA damage was repaired within $30 \mathrm{~min}$ as opposed to that of UVB $\left(0.8 \mathrm{~kJ} / \mathrm{m}^{2}\right)$, which were repaired after $24 \mathrm{~h}$ [40]. This suggests that UVB radiation induces greater damage and cell death than does UVA radiation. In addition, Schieke et al. [41] found that keratinocytes responded differently to UVA and UVB radiation alone but when a combination of radiation was used (UVA $+B$ or UVB $+A$ ), a "third" response was created that resembles neither UVA nor UVB alone.

\subsection{Effect of UV Radiation on the Activation of the p38 MAPK, JNK and NF $\kappa B$ Pathways in Melanocyte-Derived Cells}

In response to UV radiation, the p38 MAPK and JNK pathways were activated differently in HEM and MM96L cells suggesting that the UV response is a cell type-dependent effect (Figures 2 and 3). In the HEM cells, although there were differences in phospho-p38 levels, the pathway was activated in a similar pattern irrespective of the UV types and doses used (Figure 2B,D). In MM96L cells, minimal activation of phospho-p38 MAPK was seen in cells exposed to low dose UV radiation irrespective of the type used (Figure 2C). In these cells, high dose UVA and UVA + B radiation induced a dramatic increase in p38 MAPK activation while that following UVB and UVB + A radiation was low and transient (Figure 2E). In MM96L cells, this pathway appeared to be both UV wavelength and 
dose-dependent. In further support of this proposal, Liu et al. [3], found that the transcription factor MiTF was degraded in melanocytes and melanoma cells following exposure to UVA but not UVB radiation, which shows that the signaling pathways activated by both types of UV differ in these cells.

Both HEM and MM96L cells predominantly expressed higher levels of JNK1 compared to JNK2 (Figure 3). This suggests that the JNK1 isoform is selectively activated in response to UV-induced stress. Some melanoma cells (1205Lu, WM983B, sk28, WM852 and WM 793) possess a high JNK1/JNK2 ratio while others (888mel, Gerlach and WM983A) have a low ratio [8]. The exact role played by each JNK isoform in melanoma is unclear. It was shown that JNK1 siRNA inhibited cell growth in melanoma cell lines expressing high levels of JNK1 whereas JNK2 siRNA had no effect [8]. However, in WM983B melanoma cells JNK inhibition did not affect cell growth but induced apoptosis [8].

Higher levels of phospho-JNK2 were observed in UV-irradiated MM96L cells but not in HEM cells where it was almost negligible (Figure 3). In experiments involving JNK2-deficient fibroblasts, this JNK isoform was shown to be a negative regulator of cell proliferation [42]. As JNK2 is expressed in MM96L cells, its postulated role in apoptosis could have contributed to the sensitivity of these cells to UV-induced cell death (Figure 1). However, in vivo studies using JNK2 knockout mice showed that TPA-induced tumor growth was inhibited, which suggest that it is necessary for tumor proliferation [43]. Tao et al. [44] found that mice containing $\mathrm{JNK}^{-/-} \mathrm{CD}^{+} \mathrm{T}$ cells exhibited resistance to tumor proliferation and development when inoculated with $\mathrm{B} 16 \mathrm{~F} 0$ melanoma cells. This suggests that JNK2 signaling is involved in cell proliferation or cell death.

The ERK pathway has been suggested to be the main pathway involved in melanoma formation and progression [2,3,45-47]. Less is known about the role played by 338 MAPK and JNK pathways in this process. Ras and Raf are also located upstream of the p38 MAPK and JNK pathways and any mutations present in these upstream proteins will affect the ERK1/2, p38 MAPK and JNK pathways. Since MM96L cells possess B-Raf mutation [48], it may explain the higher levels of p38 and JNK in these cells post-high dose UV radiation. Estrada et al. [10] have shown that both high levels of ERK and p38 MAPK activity are required for melanoma development. These authors also found that inhibition of p38 MAPK activity alone can inhibit migration of melanoma cells [10]. The JNK pathway can be activated by ERK in a feedback loop and both pathways can activate cyclin D1 which is a positive regulator of cell cycle progression in melanoma cells [49]. Therefore, further research into the involvement of p38 MAPK and JNK, aside from the ERK, in melanoma formation is warranted.

The NFкB pathway was minimally activated in both HEM and MM96L cells in response to different UV types and doses (Figure 4). MM96L cells possessed slightly higher levels of constitutively active phospho-IкB $\alpha$ than did HEM cells. McNulty et al. [16] also found that melanocytes and melanoma cells express high constitutive levels of NFאB that were not augmented by UVB-irradiation. UVA radiation has been shown to have no effect on NFאB levels and activity in normal melanocytes [50]. These results suggest that UV radiation may not activate the NFkB pathway to the same extent as seen in the p38 MAPK and JNK pathways. It is also possible that together with the constitutive activation of $\mathrm{NF \kappa B}$, the high activation of $\mathrm{p} 38$ and JNK pathways post-UV radiation may not stimulate further NFאB activation following UV radiation. 


\subsection{Effect of UV Radiation and IL1 $\alpha$ on TNFa Release in Melanocyte-Derived Cells}

The level of TNF $\alpha$ released from both cell lines was less following UVA radiation compared to UVB radiation (Figure 5). This difference could be due to the ability of UVA radiation to selectively regulate cytokines, promote protein degradation or inhibit protein synthesis [51,52]. UVA upregulated the transcription of IL12 but at the same time inhibited that of IL10 suggesting that it may also selectively downregulate $\mathrm{TNF} \alpha$ transcription in melanocyte-derived cells [30,52]. In these cells, $\mathrm{UVA}+\mathrm{B}$ radiation caused a similar increase in TNF $\alpha$ levels to that of UVB radiation. UVB + A radiation on the other hand, decreased TNFa levels in MM96L cells but not in HEM cells (Figure 5). As UVA radiation induced less TNF $\alpha$ secretion than UVB, it is possible that in the combination of $\mathrm{UVB}+$ A radiation, the UVA component may have a suppressive effect on the release of this cytokine in MM96L cells. In HEM cells this suppressive effect brought about by UVA may have been overshadowed by the molecular interaction induced by UVB which suggests that there is a cell type-dependent response to UV radiation (Figure 5). MM96L cells do not contain large quantities of intracellular TNF $\alpha$ as determined by ELISA using cell lysates (results not shown). This suggests that the reduced level of TNFa secreted from these cells is most likely due to reduced synthesis. When IL1 $\alpha$ was added to the cells, a greater increase in TNF $\alpha$ release was observed in the UV-irradiated HEM cells compared to MM96L cells (Figure 5). TNF $\alpha$ has been shown to have a pro-survival effect in different cell lines although anti-survival effects have also been reported [11,18,53,54]. Ivanov et al. [18] found that ATF2 downregulated TNF $\alpha$ expression in UVC-irradiated $\left(0.06 \mathrm{~kJ} / \mathrm{m}^{2}\right)$ melanoma cells. Forced expression of ATF2 increased UVC-induced cell death in melanoma cells while the addition of exogenous TNF $\alpha$ restored cell survival. In this study, HEM cells were less sensitive to UV radiation than MM96L cells and it is possible that high levels of TNF $\alpha$ could have protected these cells from UV-induced cell death while the lower levels in MM96L could have made them more susceptible (Figure 1).

The addition of IL1 $\alpha$ to both cell lines in general enhanced p38 and JNK activity but not NFkB (results not shown). In order to elucidate which of these signaling pathway(s) were involved in $\mathrm{UV}+\mathrm{IL} 1 \alpha$-induced TNF $\alpha$ secretion, specific inhibitors were used. Inhibition of the p38 MAPK but not that of JNK or NFKB pathway significantly reduced TNF $\alpha$ levels in UVB-irradiated HEM cells (Figure 6A). In the UVB-irradiated MM96L cells, inhibition of either the p38 MAPK or NFkB pathways caused a partial decrease in TNF $\alpha$ levels (Figure 6B). These results suggest that the p38 MAPK pathway is the main pathway involved in regulating UV-induced release of TNF $\alpha$ from melanocyte-derived cells. Ivanov et al. [11] found that inhibition of p38 MAPK pathway led to a decrease in TNF $\alpha$ transcriptional activation. Since both p38 MAPK and NFkB inhibitors partially decreased the secretion of TNF $\alpha$ from MM96L cells, crosstalk may exist between these and other pathways as the p38 MAPK pathway was shown to be upstream of the NFkB pathway in A2058 melanoma cells [55].

In order to confirm the inhibitory effect of SB202190, anisomycin, a potent stimulator of the p38 MAPK and JNK pathways was used (Figure 7) [31]. While anisomycin increased phospho-p38 MAPK activity, it was unable to stimulate TNF $\alpha$ release in the presence or absence of IL1 $\alpha$ in sham-irradiated cells (Figure 8). This suggests that p38 MAPK-mediated TNF $\alpha$ release following UVB-irradiation may be a UV-specific response. However, when anisomycin was added to UVB-irradiated cells, TNF $\alpha$ 
release was not observed even if IL1 $\alpha$ was present (Figure 8). It is possible that UVB and anisomycin activate the p38 MAPK pathway via a different mechanism and the mode of activation might change when both stimuli are used together. In support, Ravi et al. [55] found that while caffeine or rottlerin inhibited UV-induced p38 MAPK activation neither was able to inhibit anisomycin-induced p38 MAPK activation. This suggests that UV radiation has different upstream/downstream intermediates to that of anisomycin.

In summary, HEM and MM96L exhibit different responses to UV radiation. The MAPK pathways are involved in a plethora of functions like proliferation, inflammation, apoptosis, differentiation, and cell cycle regulation among others [56,57]. As the p38 MAPK and JNK pathways are regulated differently in HEM and MM96L cells, it suggests that the functions performed by both in melanocytes may not be the same as in melanoma cells. While these pathways are usually involved in maintaining homeostasis in normal cells they may be involved in pro-tumorigenic activities in compromised cells. This may in part be due to the B-Raf mutation and other mutations acquired in MM96L cells which is upstream of the MAPK pathways. These pathways may act on their own or in conjunction with ERK to promote oncogenesis. As such, besides the ERK pathway, the p38 and JNK pathway should be probed further in identifying their supportive roles in melanomagenesis.

$\mathrm{TNF} \alpha$ secreted following irradiation is a UV specific response and the p38 MAPK pathway appears to be the main pathway involved in HEM cells but not MM96L cells, however the NFKB pathway may also be involved. Currently, the exact role played by TNF $\alpha$ in skin carcinogenesis is not known. Studies have shown that TNF $\alpha$ has a role in executing either pro- or anti-tumor activities $[11,18,20]$. Despite its dual role, identifying the pathways regulating UV-induced TNF $\alpha$ release is of importance because if it is an anti-tumor agent then pharmacological enhancers of the p38 MAPK pathway may increase its expression in targeted tumors. On the other hand, if it has a pro-tumor function, pharmacological inhibitors of the p38 MAPK pathway could be useful in reducing TNF $\alpha$ levels to eradicate skin tumors. Since the p38 MAPK pathway is also involved in normal homeostasis, the challenge would be to intervene in p38 MAPK-mediated TNF $\alpha$ release without initiating any instability within the cell by disrupting other roles of this pathway, which are responsible for normal cellular functioning. We are currently undertaking further studies on the role p38 MAPK plays in regulating TNF $\alpha$ release in UV-irradiated melanocyte-derived cells.

\section{Experimental Section}

\subsection{Materials}

All tissue culture media and supplements were obtained from Invitrogen (Melbourne, Australia) except for FBS (Foetal Bovine Serum) and BSA (Bovine Serum Albumin), which were obtained from Bovogen (Melbourne, Australia). SB203580 (p38 MAPK inhibitor), SP600125 (JNK inhibitor), NFkB Inhibitor II were from Merck (Melbourne, Australia). The chemilucent kit, Goat-HRP conjugated anti-rabbit immunoglobulin and anti-mouse immunoglobulin were obtained from Millipore (Sydney, Australia). The primary antibodies (phospho-p38 rabbit polyclonal antibody, phospho-JNK rabbit polyclonal antibody, phospho-I $\mathrm{B} \alpha$ mouse monoclonal antibody, $\beta$-actin) were from Genesearch (Gold Coast, Australia) and AccuKine Human TNF $\alpha$ ELISA Kit was from Scientifix (Melbourne, Australia). 
All other chemicals were obtained from Sigma (Sydney, Australia), unless otherwise indicated. All tissue culture vessels were obtained DKSH (Melbourne, Australia), while the Microcon YM-10 micro-concentrators were from Millipore (Sydney, Australia).

\subsection{Cell Types}

The HEM (Human Epidermal Melanocytes) cells obtained from Banksia Scientific (Brisbane, Australia) and MM96L melanoma cells [34] were kindly donated by Dr Glen Boyle (QIMR, Brisbane, Australia) were grown in culture at $37^{\circ} \mathrm{C}$. HEM cells were cultured with Medium 254 supplemented with 1\%(v/v) Human Melanocyte Growth Supplement and 1\% $(v / v)$ Penicillin-Streptomycin-Glutamine (10,000 units/mL penicillin G sodium, $10,000 \mu \mathrm{g} / \mathrm{mL}$ streptomycin sulfate and $29.2 \mathrm{mg} / \mathrm{mL}$ L-glutamine). The spent culture media was discarded and replaced with fresh media every two to three days. MM96L cells were cultured with RPMI medium 1640 supplemented with 5\% (v/v) FBS and 1\% (v/v) Penicillin-Streptomycin-Glutamine. Spent culture media was removed and discarded every three to four days and replaced with fresh RPMI media.

Subculture

When the HEM and MM96L cell cultures reached confluence, the respective spent culture media were aspirated and the cells washed twice with sterile phosphate-buffered saline (PBS) and once with Trypsin-EDTA solution. After which, the cells were incubated with sterile Trypsin-EDTA solution and the trypsinized cells were used to seed the petri dishes or 6-well plates used in experiments. All solutions used in tissue culture were kept at $37^{\circ} \mathrm{C}$ for MM96L cells and at RT $\left(20^{\circ} \mathrm{C}\right)$ for HEM cells unless specified otherwise.

\subsection{UV-Irradiation}

The UV cabinet (Wayne Electronics, Sydney, Australia) housed 6 UV fluorescent lamps: 3 UVA Phillips Ultraviolet TLK 40W/10 R lamps (Phillips, Eindhoven, Holland) and 3 UVB Phillips Ultraviolet TL 20W/01 RS lamps (Phillips, Eindhoven, Holland). The UV light emitted from UVA lamps ranged from 350 to $400 \mathrm{~nm}$ with a peak at $365 \mathrm{~nm}$ while that of UVB lamps (305-315 nm) had a maximal output at 311-312 nm [58,59]. The variation in the output $\left(\mathrm{mW} / \mathrm{cm}^{2}\right)$ of the UV lamps was measured using a relevant UV detector (UVA or UVB) attached to an IL-1400A Photometer (International Light, Newburyport, USA). The low and high doses used in this study represented the respective UV (A and B) components of either 0.1 or 1 MED [22]. Kuchel et al. [60] found that the average UV dose to induce 1 MED was $41 \pm 2 \mathrm{~kJ} / \mathrm{m}^{2}$ when exposed to solar simulated UV light. As it is estimated that the UVA and UVB component of sunlight is $95 \%$ and $5 \%$ respectively, $40 \mathrm{~kJ} / \mathrm{m}^{2}$ of UVA and $2 \mathrm{~kJ} / \mathrm{m}^{2}$ of UVB was chosen to represent 1 MED of solar sunlight $\left(40 \mathrm{~kJ} / \mathrm{m}^{2}\right)$ while a tenth of these doses (UVA: $4 \mathrm{~kJ} / \mathrm{m}^{2}$ and UVB: $0.2 \mathrm{~kJ} / \mathrm{m}^{2}$ ) represented 0.1 MED. When the cells were exposed to both UVA and UVB radiation, as it was not possible to simultaneously irradiate with both UV types they were exposed initially first to either UVA (denoted UVA + B) or UVB (denoted UVB + A). The irradiation protocol was performed as described by Huynh et al. [61]. 


\subsection{Cell Viability}

Cell viability was determined $24 \mathrm{~h}$ post-UV radiation using the Trypan Blue exclusion method [61].

\subsection{Inhibitor and Anisomycin Studies}

All the signaling pathway inhibitors and anisomycin were dissolved in DMSO. In the inhibitor studies, cells cultured in $60 \mathrm{~mm}$ petri dishes were pre-treated for $1 \mathrm{~h}$ with either $2.5 \mu \mathrm{M} \mathrm{SB} 203580$ (p38 MAPK inhibitor, Stock solution: $2 \mathrm{mM}$ ), $2.5 \mu \mathrm{M}$ SP600125 (JNK inhibitor, Stock solution: $2 \mathrm{mM}$ ) or $0.625 \mathrm{mM}$ sulfasalazine (NFKB inhibitor, Stock solution: $0.25 \mathrm{M}$ ). After which the inhibitor solution was removed and the cell culture was irradiated. Immediately following radiation, the inhibitor solution was added to the culture and was incubated for various time points as seen in the results section. In the anisomycin studies, irradiated cell cultures were incubated with $20-100 \mu \mathrm{M}$ anisomycin (Stock solution: $20 \mathrm{mM}$ ) for various time points as seen in the results section.

\subsection{Western Blotting}

The cells were harvested $0-120$ min post-irradiation as previously described [17,61]. The nylon membranes were incubated with the relevant antibody [1:1000 phospho-p38 rabbit polyclonal antibody, 1:1000 phospho-JNK rabbit polyclonal antibody, 1:1000 phospho-IкB $\alpha$ mouse monoclonal antibody, 1:1000 $\beta$-actin (loading control)] overnight at $4{ }^{\circ} \mathrm{C}$. After which, they were incubated with the appropriate secondary antibody (1:1000 Goat-HRP conjugated anti-rabbit immunoglobin or 1:1000 Sheep HRP conjugated anti-mouse immunoglobin). The membranes were developed in Chemilucent solution and visualized using a Chemidox XRS unit (BioRad). The digital image was analyzed for densitometry using Quantity One Digital Imaging Software Version 4.5.1 (BioRad). The intensity of the expression of the phosphorylated signaling intermediate was first normalized to that of its loading control $\beta$-actin, and for the sham-irradiated untreated controls this was expressed as $100 \%$. The value for the phosphorylated signaling intermediate at each time point was compared to that of the sham-irradiated controls and was expressed as a percentage.

\subsection{ELISA}

The levels of TNF $\alpha$ released from the UV-irradiated cell cultures were measured $24 \mathrm{~h}$ post-irradiation. Immediately after UV exposure, fresh media was added to the cells. In some experiments, $10 \mathrm{ng} / \mathrm{mL}$ of IL1 $\alpha$ was added to the media as it stimulates TNF $\alpha$ release from UV-irradiated keratinocytes [30]. Aliquots of the culture media were concentrated using Microcon YM-10 micro-concentrators. The levels of TNF $\alpha$ in these media samples were determined using an AccuKine Human TNF $\alpha$ ELISA Kit.

\subsection{Statistical Analysis}

The results obtained in this study were expressed as the mean \pm standard deviation (SD) from triplicate samples. The statistical significance was determined by the use of Student's paired, one-tailed $t$-test with $p \leq 0.05$ deemed to be significant. 


\section{Conclusions}

We have found that the MAPK pathways are activated differently in normal and compromised melanocytes. Furthermore, we have found that the p38 pathway plays a major role in the secretion of an inflammatory molecule, TNF $\alpha$ in UV-irradiated melanocyte-derived cells but not via anisomycin-activated p38 MAPK pathway. Therefore, further investigation into the signaling intermediates regulating TNF $\alpha$ secretion in UV-irradiated melanocytes and melanoma cells is warranted.

\section{Acknowledgments}

We acknowledge funding from the School of Medical Sciences' (RMIT University) Student Support Grant and National Health and Medical Research Council Grant (No. 616621). VM was the recipient of a School of Medical Sciences (RMIT University) Postgraduate Research Student Scholarship.

\section{Conflicts of Interest}

The authors declare no conflict of interest.

\section{References}

1. Muthusamy, V.; Piva, T.J. Melanoma Cell Signaling: Looking Beyond RAS-RAF-MEK. In Skin Cancers-Risk Factors, Prevention and Therapy; Porta, C.L., Ed.; InTech: Rijeka, Croatia, 2011; pp. 87-108.

2. Sullivan, R.J.; Flaherty, K. MAP kinase signaling and inhibition in melanoma. Oncogene 2013, 32, 2373-2379.

3. Liu, F.; Singh, A.; Yang, Z.; Garcia, A.; Kong, Y.; Meyskens, F.L., Jr. MiTF links Erk1/2 kinase and $\mathrm{p} 21^{\mathrm{CIP} 1 / \mathrm{WAF} 1}$ activation after UVC radiation in normal human melanocytes and melanoma cells. Mol. Cancer 2010, 9, 214.

4. Enzler, T.; Sano, Y.; Choo, M.K.; Cottam, H.B.; Karin, M.; Tsao, H.; Park, J.M. Cell-selective inhibition of NFKB signaling improves therapeutic index in a melanoma chemotherapy model. Cancer Discov. 2011, 1, 496-507.

5. Keuling, A.M.; Andrew, S.E.; Tron, V.A. Inhibition of p38 MAPK enhances ABT-737-induced cell death in melanoma cell lines: Novel regulation of PUMA. Pigment Cell Melanoma Res. 2010, $23,430-440$.

6. Selimovic, D.; Hassan, M.; Haikel, Y.; Hengge, U.R. Taxol-induced mitochondrial stress in melanoma cells is mediated by activation of c-Jun N-terminal kinase (JNK) and p38 pathways via uncoupling protein 2. Cell Signal 2008, 20, 311-322.

7. Shieh, J.M.; Huang, T.F.; Hung, C.F.; Chou, K.H.; Tsai, Y.J.; Wu, W.B. Activation of c-jun $\mathrm{N}$-terminal kinase is essential for mitochondrial membrane potential change and apoptosis induced by doxycycline in melanoma cells. Br. J. Pharmacol. 2010, 160, 1171-1184.

8. Alexaki, V.I.; Javelaud, D.; Mauviel, A. JNK supports survival in melanoma cells by controlling cell cycle arrest and apoptosis. Pigment Cell Melanoma Res. 2008, 21, 429-438. 
9. Denkert, C.; Siegert, A.; Leclere, A.; Turzynski, A.; Hauptmann, S. An inhibitor of stress-activated MAP-kinases reduces invasion and MMP-2 expression of malignant melanoma cells. Clin. Exp. Metastasis 2002, 19, 79-85.

10. Estrada, Y.; Dong, J.; Ossowski, L. Positive crosstalk between ERK and p38 in melanoma stimulates migration and in vivo proliferation. Pigment Cell Melanoma Res. 2009, 22, 66-76.

11. Ivanov, V.N.; Fodstad, O.; Ronai, Z. Expression of ring finger-deleted TRAF2 sensitizes

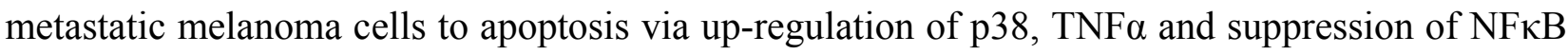
activities. Oncogene 2001, 20, 2243-2253.

12. Kannaiyan, R.; Manu, K.A.; Chen, L.; Li, F.; Rajendran, P.; Subramaniam, A.; Lam, P.; Kumar, A.P.; Sethi, G. Celastrol inhibits tumor cell proliferation and promotes apoptosis through the activation of c-Jun N-terminal kinase and suppression of PI3K/Akt signaling pathways. Apoptosis 2011, 16, 1028-1041.

13. Ke, H.; Augustine, C.K.; Gandham, V.D.; Jin, J.Y.; Tyler, D.S.; Akiyama, S.K.; Hall, R.P.; Zhang, J.Y. Cyld inhibits melanoma growth and progression through suppression of the JNK/AP-1 and $\beta 1$-integrin signaling pathways. J. Investig. Dermatol. 2013, 133, 221-229.

14. Hayden, M.S.; Ghosh, S. Signaling to NFkB. Genes Dev. 2004, 18, 2195-2224.

15. McNulty, S.E.; del Rosario, R.; Cen, D.; Meyskens, F.L., Jr.; Yang, S. Comparative expression of $\mathrm{NF} \kappa \mathrm{B}$ proteins in melanocytes of normal skin $v s$. benign intradermal naevus and human metastatic melanoma biopsies. Pigment Cell Res. 2004, 17, 173-180.

16. McNulty, S.E.; Tohidian, N.B.; Meyskens, F.L., Jr. RelA, p50 and inhibitor of $\kappa \mathrm{B} \alpha$ are elevated in human metastatic melanoma cells and respond aberrantly to ultraviolet light B. Pigment Cell Res. 2001, 14, 456-465.

17. Muthusamy, V.; Hodges, L.D.; Macrides, T.A.; Boyle, G.M.; Piva, T.J. Effect of novel marine nutraceuticals on IL-1 $\alpha$-mediated TNF $\alpha$ release from UVB-irradiated human melanocyte-derived cells. Oxid. Med. Cell Longev. 2011, 2011, 728645.

18. Ivanov, V.N.; Ronai, Z. Down-regulation of tumor necrosis factor $\alpha$ expression by activating transcription factor 2 increases UVC-induced apoptosis of late-stage melanoma cells. J. Biol. Chem. 1999, 274, 14079-14089.

19. Gray-Schopfer, V.C.; Karasarides, M.; Hayward, R.; Marais, R. Tumor necrosis factor- $\alpha$ blocks apoptosis in melanoma cells when BRAF signaling is inhibited. Cancer Res. 2007, 67, 122-129.

20. Tandle, A.; Hanna, E.; Lorang, D.; Hajitou, A.; Moya, C.A.; Pasqualini, R.; Arap, W.; Adem, A.; Starker, E.; Hewitt, S.; et al. Tumor vasculature-targeted delivery of tumor necrosis factor- $\alpha$. Cancer 2009, 115, 128-139.

21. Ivanov, V.N.; Ronai, Z. p38 protects human melanoma cells from UV-induced apoptosis through down-regulation of NFKB activity and Fas expression. Oncogene 2000, 19, 3003-3012.

22. Halliday, G.M.; Lyons, J.G. Inflammatory doses of UV may not be necessary for skin carcinogenesis. Photochem. Photobiol. 2008, 84, 272-283.

23. Muthusamy, V.; Piva, T.J. The UV response of the skin: A review of the MAPK, NFkB and TNF $\alpha$ signal transduction pathways. Arch. Dermatol. Res. 2010, 302, 5-17.

24. Johnson, G.L.; Nakamura, K. The c-Jun kinase/stress-activated pathway: Regulation, function and role in human disease. Biochim. Biophys. Acta 2007, 1773, 1341-1348.

25. Hayden, M.S.; Ghosh, S. Shared principles in NFאB signaling. Cell 2008, 132, 344-362. 
26. Devalaraja, M.N.; Wang, D.Z.; Ballard, D.W.; Richmond, A. Elevated constitutive IкB kinase activity and $\mathrm{I} \kappa \mathrm{B} \alpha$ phosphorylation in Hs294T melanoma cells lead to increased basal MGSA/GRO $\alpha$ transcription. Cancer Res. 1999, 59, 1372-1377.

27. Clydesdale, G.J.; Dandie, G.W.; Muller, H.K. Ultraviolet light induced injury: Immunological and inflammatory effects. Immunol. Cell Biol. 2001, 79, 547-568.

28. Duthie, M.S.; Kimber, I.; Norval, M. The effects of ultraviolet radiation on the human immune system. Br. J. Dermatol. 1999, 140, 995-1009.

29. Ullrich, S.E.; Byrne, S.N. The immunologic revolution: Photoimmunology. J. Investig. Dermatol. 2012, 132, 896-905.

30. Bashir, M.M.; Sharma, M.R.; Werth, V.P. UVB and proinflammatory cytokines synergistically activate $\mathrm{TNF} \alpha$ production in keratinocytes through enhanced gene transcription. J. Investig. Dermatol. 2009, 129, 994-1001.

31. Hazzalin, C.A.; Le Panse, R.; Cano, E.; Mahadevan, L.C. Anisomycin selectively desensitizes signaling components involved in stress kinase activation and fos and jun induction. Mol. Cell Biol. 1998, 18, 1844-1854.

32. Johansson, P.; Pavey, S.; Hayward, N. Confirmation of a BRAF mutation-associated gene expression signature in melanoma. Pigment Cell Res. 2007, 20, 216-221.

33. Castellano, M.; Pollock, P.M.; Walters, M.K.; Sparrow, L.E.; Down, L.M.; Gabrielli, B.G.; Parsons, P.G.; Hayward, N.K. CDKN2A/p16 is inactivated in most melanoma cell lines. Cancer Res. 1997, 57, 4868-4875.

34. Pope, J.H.; Morrison, L.; Moss, D.J.; Parsons, P.G.; Regius Mary Sister. Human malignant melanoma cell lines. Pathology 1979, 11, 191-195.

35. Kadekaro, A.L.; Kavanagh, R.J.; Wakamatsu, K.; Ito, S.; Pipitone, M.A.; Abdel-Malek, Z.A. Cutaneous photobiology. The melanocyte vs. the sun: Who will win the final round? Pigment Cell Res. 2003, 16, 434-447.

36. Kaidbey, K.H.; Agin, P.P.; Sayre, R.M.; Kligman, A.M. Photoprotection by melanin-A comparison of black and caucasian skin. J. Am. Acad. Dermatol. 1979, 1, 249-260.

37. Kobayashi, N.; Nakagawa, A.; Muramatsu, T.; Yamashina, Y.; Shirai, T.; Hashimoto, M.W.; Ishigaki, Y.; Ohnishi, T.; Mori, T. Supranuclear melanin caps reduce ultraviolet induced DNA photoproducts in human epidermis. J. Investig. Dermatol. 1998, 110, 806-810.

38. Yohn, J.J.; Norris, D.A.; Yrastorza, D.G.; Buno, I.J.; Leff, J.A.; Hake, S.S.; Repine, J.E. Disparate antioxidant enzyme activities in cultured human cutaneous fibroblasts, keratinocytes, and melanocytes. J. Investig. Dermatol. 1991, 97, 405-409.

39. Koch-Paiz, C.A.; Amundson, S.A.; Bittner, M.L.; Meltzer, P.S.; Fornace, A.J., Jr. Functional genomics of UV radiation responses in human cells. Mutat. Res. 2004, 549, 65-78.

40. Besaratinia, A.; Kim, S.I.; Pfeifer, G.P. Rapid repair of UVA-induced oxidized purines and persistence of UVB-induced dipyrimidine lesions determine the mutagenicity of sunlight in mouse cells. FASEB J. 2008, 22, 2379-2392.

41. Schieke, S.M.; Ruwiedel, K.; Gers-Barlag, H.; Grether-Beck, S.; Krutmann, J. Molecular crosstalk of the ultraviolet $\mathrm{A}$ and ultraviolet $\mathrm{B}$ signaling responses at the level of mitogen-activated protein kinases. J. Investig. Dermatol. 2005, 124, 857-859. 
42. Sabapathy, K.; Wagner, E.F. Jnk2: A negative regulator of cellular proliferation. Cell Cycle 2004, $3,1520-1523$.

43. Chen, N.; Nomura, M.; She, Q.B.; Ma, W.Y.; Bode, A.M.; Wang, L.; Flavell, R.A.; Dong, Z. Suppression of skin tumorigenesis in c-Jun $\mathrm{NH}_{2}$-terminal kinase-2-deficient mice. Cancer Res. 2001, 61, 3908-3912.

44. Tao, J.; Gao, Y.; Li, M.O.; He, W.; Chen, L.; Harvev, B.; Davis, R.J.; Flavell, R.A.; Yin, Z. JNK2 negatively regulates $\mathrm{CD} 8^{+} \mathrm{T}$ cell effector function and anti-tumor immune response. Eur. J. Immunol. 2007, 37, 818-829.

45. Alsina, J.; Gorsk, D.H.; Germino, F.J.; Shih, W.; Lu, S.E.; Zhang, Z.G.; Yang, J.M.; Hait, W.N.; Goydos, J.S. Detection of mutations in the mitogen-activated protein kinase pathway in human melanoma. Clin. Cancer Res. 2003, 9, 6419-6425.

46. Hoshino, R.; Chatani, Y.; Yamori, T.; Tsuruo, T.; Oka, H.; Yoshida, O.; Shimada, Y.; Ari-i, S.; Wada, H.; Fujimoto, J.; et al. Constitutive activation of the 41-/43-kDa mitogen-activated protein kinase signaling pathway in human tumors. Oncogene 1999, 18, 813-822.

47. Collisson, E.A.; de, A.; Suzuki, H.; Gambhir, S.S.; Kolodney, M.S. Treatment of metastatic melanoma with an orally available inhibitor of the Ras-Raf-MAPK cascade. Cancer Res. 2003, 63, 5669-5673.

48. Pavey, S.; Johansson, P.; Packer, L.; Taylor, J.; Stark, M.; Pollock, P.M.; Walker, G.J.; Boyle, G.M.; Harper, U.; Cozzi, S.J.; et al. Microarray expression profiling in melanoma reveals a BRAF mutation signature. Oncogene 2004, 23, 4060-4067.

49. Lopez-Bergami, P.; Huang, C.; Goydos, J.S.; Yip, D.; Bar-Eli, M.; Herlyn, M.; Smalley, K.S.; Mahale, A.; Eroshkin, A.; Aaronson, S.; et al. Rewired ERK-JNK signaling pathways in melanoma. Cancer Cell 2007, 11, 447-460.

50. Shang, J.; Schwarz, C.; Sanchez Ruderisch, H.; Hertting, T.; Orfanos, C.E.; Tebbe, B. Effects of UVA and L-ascorbic acid on nuclear factor- $\kappa \mathrm{B}$ in melanocytes and in HaCaT keratinocytes. Skin Pharmacol. Appl. Skin Physiol. 2002, 15, 353-359.

51. Djavaheri-Mergny, M.; Gras, M.P.; Mergny, J.L.; Dubertret, L. UVA-induced decrease in nuclear factor- $\kappa \mathrm{B}$ activity in human keratinocytes. Biochem. J. 1999, 338, 607-613.

52. Kondo, S.; Jimbow, K. Dose-dependent induction of IL-12 but not IL-10 from human keratinocytes after exposure to ultraviolet light a. J. Cell Physiol. 1998, 177, 493-498.

53. Basile, J.R.; Eichten, A.; Zacny, V.; Munger, K. NF-kB-mediated induction of $\mathrm{p} 21^{\text {(cip1/waf1) }}$ by tumor necrosis factor $\alpha$ induces growth arrest and cytoprotection in normal human keratinocytes. Mol. Cancer Res. 2003, 1, 262-270.

54. Szoltysek, K.; Pietranek, K.; Kalinowska-Herok, M.; Pietrowska, M.; Kimmel, M.; Widlak, P. $\mathrm{TNF} \alpha$-induced activation of $\mathrm{NF \kappa B}$ protects against UV-induced apoptosis specifically in p53-proficient cells. Acta Biochim. Pol. 2008, 55, 741-748.

55. Ravi, D.; Muniyappa, H.; Das, K.C. Caffeine inhibits UV-mediated NFкB activation in A2058 melanoma cells: An ATM-PKC $\delta$-p38 MAPK-dependent mechanism. Mol. Cell Biochem. 2008, 308, 193-200.

56. Jinlian, L.; Yingbin, Z.; Chunbo, W. p38 MAPK in regulating cellular responses to ultraviolet radiation. J. Biomed. Sci. 2007, 14, 303-312. 
57. Weston, C.R.; Davis, R.J. The JNK signal transduction pathway. Curr. Opin. Cell Biol. 2007, 19, 142-149.

58. Krohne, T.U.; Hunt, S.; Holz, F.G. Effect of $308 \mathrm{~nm}$ excimer laser irradiation on retinal pigment epithelium cell viability in vitro. Br. J. Ophthalmol. 2009, 93, 91-95.

59. Mikita, N.; Kanazawa, N.; Yoshimasu, T.; Ikeda, T.; Li, H.J.; Yamamoto, Y.; Furukawa, F. The protective effects of ultraviolet A1 irradiation on spontaneous lupus erythematosus-like skin lesions in MRL/lpr mice. Clin. Dev. Immunol. 2009, 2009, 673952.

60. Kuchel, J.M.; Barnetson, R.S.; Halliday, G.M. Ultraviolet A augments solar-simulated ultraviolet radiation-induced local suppression of recall responses in humans. J. Investig. Dermatol. 2002, $118,1032-1037$.

61. Huynh, T.T.; Chan, K.S.; Piva, T.J. Effect of ultraviolet radiation on the expression of pp38MAPK and furin in human keratinocyte-derived cell lines. Photodermatol. Photoimmunol. Photomed. 2009, 25, 20-29.

(C) 2013 by the authors; licensee MDPI, Basel, Switzerland. This article is an open access article distributed under the terms and conditions of the Creative Commons Attribution license (http://creativecommons.org/licenses/by/3.0/). 